\title{
Immune Reconstitution of B Cells Following Allogeneic Hematopoietic Cell Transplantation
}

\section{Citation}

Aboalela, Ali Anwar. 2015. Immune Reconstitution of B Cells Following Allogeneic Hematopoietic Cell Transplantation. Doctoral dissertation, Harvard School of Dental Medicine.

\section{Permanent link}

http://nrs.harvard.edu/urn-3:HUL.InstRepos:17331949

\section{Terms of Use}

This article was downloaded from Harvard University's DASH repository, and is made available under the terms and conditions applicable to Other Posted Material, as set forth at http:// nrs.harvard.edu/urn-3:HUL.InstRepos:dash.current.terms-of-use\#LAA

\section{Share Your Story}

The Harvard community has made this article openly available.

Please share how this access benefits you. Submit a story.

\section{Accessibility}




\title{
Immune reconstitution of $B$ cells following allogeneic hematopoietic cell transplantation
}

\author{
A Thesis Presented by \\ Ali Anwar Aboalela \\ To \\ The Faculty of Medicine \\ In partial fulfillment of the requirements \\ For the degree of \\ Doctor of Medical Sciences \\ Research Mentor: Jerome Ritz, MD \\ HMS and DFCI \\ Research contributors: Haesook T. Kim, PhD; Ana Alho MD; \\ Carol G. Reynolds, PhD and Marie J. Chammas \\ Harvard School of Dental Medicine \\ Boston, Massachusetts
}

May, 2015 


\section{Table of Contents:}

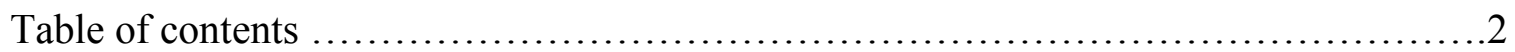

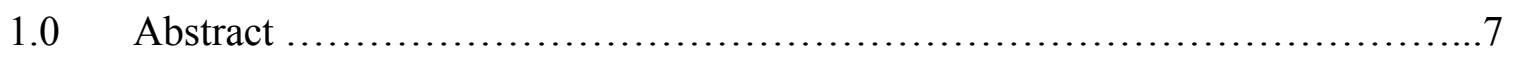

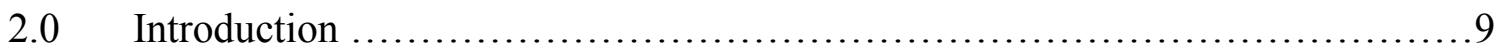

Literature Review ................................................... 12

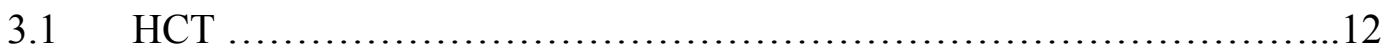

3.2 Immune reconstitution following allogeneic transplantation ............13

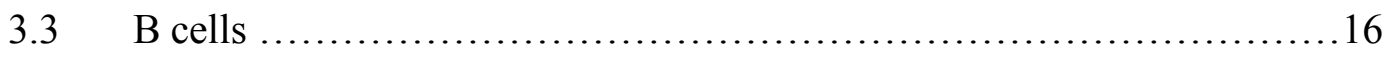

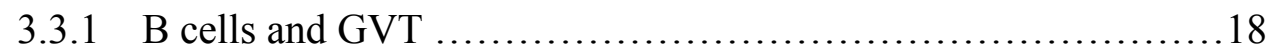

3.3.2 B cells and cGVHD ......................................... 18

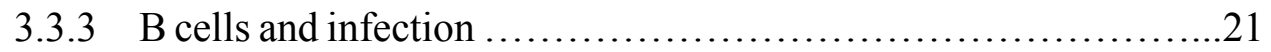

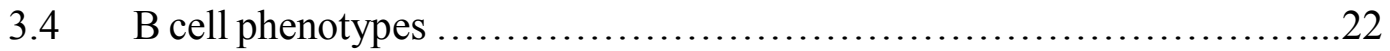

3.4.1 CD19+ and CD20+ ....................................22

3.4.2 CD19+CD27- and CD19+CD27+ .........................23

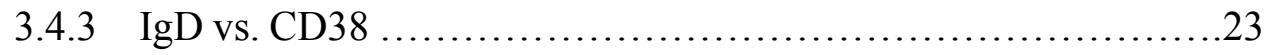

3.4.4 CD19+ CD27- IgD + CD38+ B cells ........................24

3.4.5 CD19+ CD27- IgD + CD38 low/- B cells ....................25

3.4.6 CD19+ CD27+ IgD+ CD38 low/- B cells ...................26 
3.4.7 $\mathrm{CD} 19+\mathrm{CD} 27+\mathrm{IgD}+\mathrm{CD} 38+\mathrm{B}$ cells $\ldots \ldots \ldots \ldots \ldots \ldots \ldots \ldots \ldots . \ldots \ldots$

3.4.8 CD19+ CD27+ IgD low/- CD38 low/- B cells .................27

3.4.9 CD19+ CD27+ IgD low/- CD38+ plasmablasts ................28

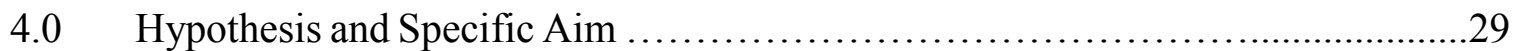

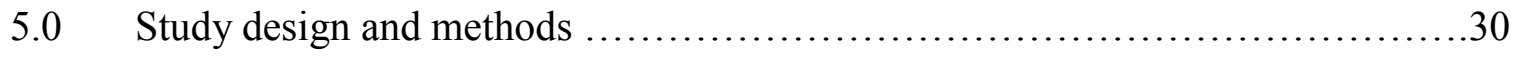

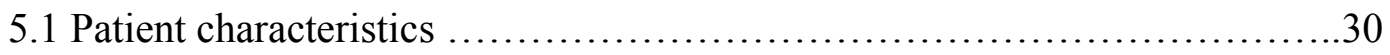

5.1.1 Inclusion criteria ...............................................

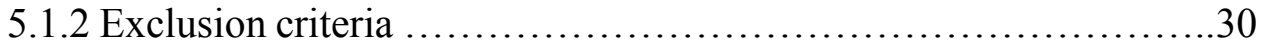

5.1.3 Preparative regimen .............................................

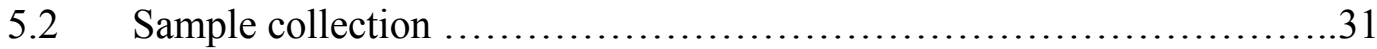

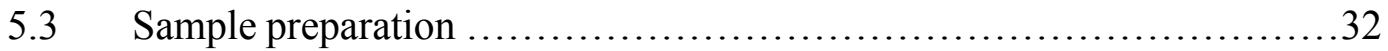

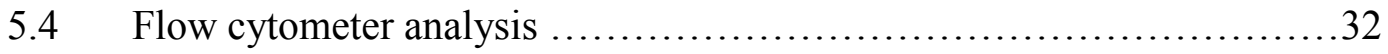

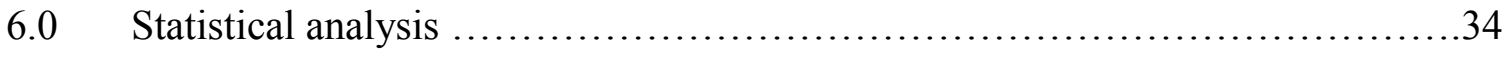

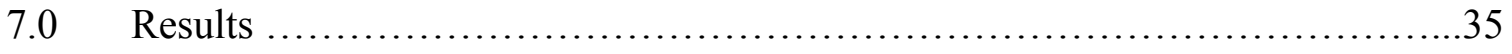

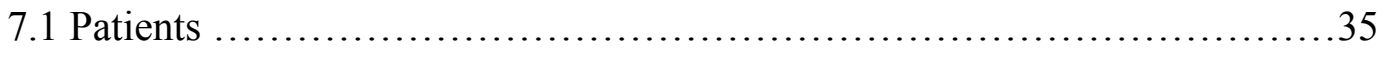

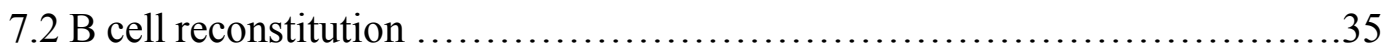

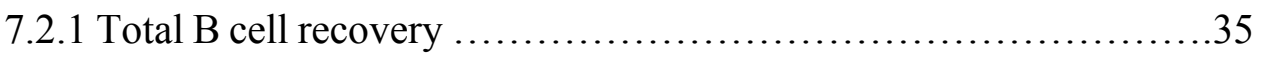

7.2.2 Antigen Naïve B cell and subsets ..............................36 
Table 1: B cell subsets identified in peripheral blood

Table 2: TP 764 myeloablative conditioning regimen

Table 3: TP 855 reduced intensity conditioning regimen .66

Table 4: Fluorophore-conjugated monoclonal antibodies specific for

B cell surface markers

Figure 1: Gating of major subgroups, lymphocytes, CD45, CD20 and

CD19+CD27+/.68

Figure 2: $\mathrm{B}$ cell subsets as gated $\mathrm{IgD}$ vs $\mathrm{CD} 38$ .69

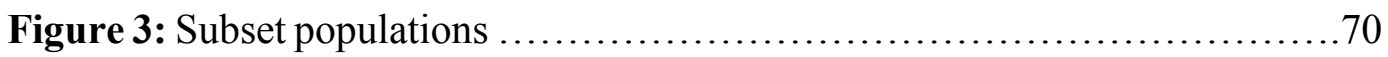

Table 5: Baseline Characteristics ........................................... 71

Table 6: Absolute numbers of total B cells months' 1-36 post HCT vs HD .......73

Figure 4: Recovery of total $\mathrm{B}$ cells vs HD ..................................73 
Table 7: Absolute number of antigen experienced month 1-36

post HCT vs HD................................................... 74

Figure 5: Absolute number of antigen experienced vs HD ....................74

Table 8: Frequency of antigen experienced months' 1-36 post HCT vs HD .....75

Figure 6: Frequency of antigen experienced B cells vs HD ..................75

Table 9: Absolute numbers of antigen naïve months' 1-36 post HCT vs HD .....76

Figure 7: Absolute numbers of antigen naïve vs HD ......................76

Table 10: Frequency of transitional B cells months' 1-36 post HCT vs HD .....77

Table 11: Frequency of naive B cells months' 1-36 post HCT vs HD ...........77

Figure 8: Frequency of transitional B cells vs HD ....................... 78

Figure 9: Frequency of naïve B cells vs HD ...........................78

Table 12: Frequency of IgD memory B cells months' 1-36 post HCT vs HD .....79

Figure 10: Frequency of IgD memory B cells vs HD ...................... 79

Table 13: Frequency of pre germinal B cells months' 1-36 post HCT vs HD .....80

Figure 11: Frequency of pre germinal B cells vs HD ........................ 80

Table 14: Frequency of post germinal B cells months' 1-36 post HCT vs HD ...81

Figure 12: Frequency of post germinal B cells vs HD ........................ 81

Table 15: Frequency of plasmablasts vs HD .............................. 82

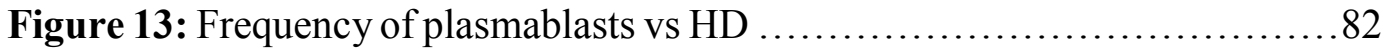


Table 16: Absolute numbers of total B cells MAC vs RIC months' 1-36 post

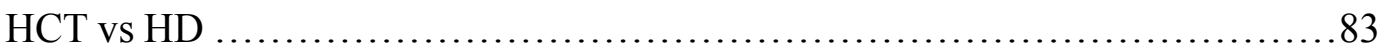

Figure 14: Absolute numbers of total B cells MAC vs RIC ...................83

Table 17: Absolute numbers of antigen experienced cells MAC vs RIC months'

$1-36$ post HCT vs HD .............................................. 84

Figure 15: Absolute numbers of antigen experienced cells MAC vs RIC .......84

Table 18: Frequency of B cell subsets MAC vs RIC $\ldots \ldots \ldots \ldots \ldots \ldots \ldots \ldots \ldots . \ldots 5$

Figure 16: Frequency profile of transitional B cells MAC vs RIC .............87

Figure 17: Frequency profile of naïve B cells MAC vs RIC $\ldots \ldots \ldots \ldots \ldots \ldots \ldots . .87$

Figure 18: Frequency profile of pre germinal B cells MAC vs RIC $\ldots \ldots \ldots \ldots \ldots . . .88$

Figure 19: Frequency profile of post germinal B cells MAC vs RIC .............88

Figure 20: Frequency profile of IgD memory B cells MAC vs RIC ...........89

Figure 21: Frequency profile of plasmablasts MAC vs RIC .................89 


\section{$\underline{1.0 \text { Abstract }}$}

Objectives: Graft versus host disease (GVHD), infections and disease relapse continue to be major complications of allogeneic hematopoietic cell transplantation (HCT). B cell abnormalities have been associated with these complications, and the objective of these studies was to identify and quantify abnormalities of B cell recovery after allogeneic HCT.

Methods: Flow cytometry was used to analyze peripheral blood from healthy donors (HD) and samples obtained at 1, 2, 3, 6, 9, 12, 18, 24, 30, and 36 months post HCT. A panel of 8 fluorophore-conjugated monoclonal antibodies specific for B cell surface markers was used to identify levels of total B cells, antigen naïve, antigen experienced, transitional B cells, naïve B cells, IgD memory, pre germinal, post germinal, and plasmablasts.

Results: 224 male patients and 175 female patients (total N=399) with a median age of 58 years (range 19-74) were included in this study. 308 patients received reduced intensity and 91 received myeloablative conditioning for allogeneic HCT in the management of various hematological malignancies. The 2 -year overall survival was $65 \%$ and progression free survival was $55 \%$.

The absolute number of total B cells in patients compared to HD remained low for 9 months $\left(118.8 \times 10^{6} / \mathrm{L}\right.$ vs $\left.204 \times 10^{6} / \mathrm{L}, \mathrm{P}<0.02\right)$ and normal levels were reached by 
month 12. Recovering cells were primarily antigen naïve B cells and the frequency of antigen experienced B cells remained below normal when compared to HD for all time points post $\mathrm{HCT}(\mathrm{P}<0.0001)$.

Within the antigen naïve compartment, the frequency of transitional B cells remained elevated and naïve B cells remained below normal until normal levels were reached by month 9 . Within the antigen experienced compartment, the frequency of pre germinal cells was elevated compared to HD from 6 months $(4.8 \%$ vs $0.70 \% ; \mathrm{P}<0.0002)$ post HCT. Plasmablast frequencies were elevated compared to HD from 6 months $(7.3 \%$ vs $1.1 \% ; \mathrm{P}<0.0009)$ post HCT. IgD memory cells did not reach normal frequency for most time points. Post germinal cells did not reach normal frequencies from 6 to 12 months post HCT.

Conclusion: Disturbances in B cell maturation after HCT persist for prolonged periods despite recovery of normal numbers of circulating B cells. Naïve and transitional B cells that predominate have low affinity BCRs and have been implicated in cGVHD. Reduced numbers of high affinity antigen experienced B cells likely predispose patients to infectious complications post HCT. 


\section{$\underline{2.0 \text { Introduction }}$}

The increased understanding of hematopoietic malignancies over the years has led to the improvement in diagnostics and treatment of both bone marrow disorders and hematological malignancies. Diseases thought to be incurable like myelodysplastic syndrome (MDS), acute myeloid leukemia (AML), acute lymphoblastic leukemia (ALL) and lymphoma are now better managed with the goal to cure. This has been made possible by a wide array of treatment options now widely available to the clinician, including new chemotherapeutic agents, antigen specific targeted therapy, and hematopoietic cell transplantation (HCT) whether autologous or allogeneic.

Allogeneic HCT is an accepted form of treatment modality, of hematological disorders/malignancies, with the intent to cure. The development of enhanced treatment strategies preceding allogeneic transplant, and improved supportive care following the transplant has led to better long-term survival ${ }^{1}$. A critical factor for long term survival and eventually decreasing the need of supportive care is the establishment of an effective immune reconstitution following transplant. The role of an effective immune reconstitution following HCT is essential in limiting disease relapse, infections, secondary malignancies and graft versus host disease (GVHD).

Disease relapse remains to be a major cause of mortality, particularly within the first two years post-transplant. Engraftment of donor hematopoietic cells, and 
reconstitution of a functional immune system, can play a critical role in preventing disease relapse by inducing a graft versus tumor (GVT) effect. GVT involves the recognition of recipient tumor cells by donor immune cells, and the subsequent rejection of tumor cells, in so doing preventing disease relapse. This further emphasizes the need of establishing a functional immune system in an attempt to establish a long lasting tumor cell rejection. The recognition of GVT and its effects led to the introduction of reduced intensity conditioning (RIC) regimens (prior to transplantation) and donor lymphocyte infusions (DLI) posttransplantation taking advantage of the immunologic response of donor cells to tumor cells 2,3 .

Chronic graft-versus-host disease (cGVHD) is another major complication of allogeneic HCT. cGVHD is associated with significant morbidity, and remains to be the leading cause of non-relapse mortality ${ }^{1,4}$. Studies showing the impact of elevated B cell activating factor (BAFF) levels and aberrant B cell reconstitution has suggested that B cells may play an important role in the pathogenesis of cGVHD.

Another cause of significant morbidity/mortality in the HCT population is the increased susceptibility of patients to microbial infections. Susceptibility to infections in the early post-transplant period are serious due to low nadirs and dysregulation of all immune compartments. For later periods after transplantation and after immune cells like neutrophils and NK cells recover patients remain susceptible although to a lesser extent due to dysregulation of the lymphocyte compartment (T and B cells $)^{5}$. 
Although total B cell recovery after HCT has previously been reported, the process of B cell maturation after HCT has not been well defined and characterization of abnormal B cell maturation in a large patient cohort will facilitate the subsequent examination of the potential clinical significance of these abnormalities. We hypothesized that aberrant maturation of B cells will persist even when quantitative B cell recovery has been achieved. 


\section{$\underline{\text { 3.0 Literature Review }}$}

\section{$\underline{3.1 \mathrm{HCT}}$}

Transplantation involves the infusion of hematopoietic stem cells following a preparative regimen that consists of radiotherapy, chemotherapy or a combination of both. The two main types of HCT are autologous and allogeneic, the first involving the collection of stem cells from the same individual (with the disorder/disease) to be re-infused at a later date as a form of rescue, in the second situation stem cells are collected from another individual without the disorder and infused into the recipient.

According to the World health organization over 50,000 transplants are performed worldwide every year. Improved access to donor registries like the Bone marrow donors worldwide (with over 25 million registered donors) have allowed the substantial increase in the number of performed transplants per year. Other factors positively impacting the utilization of allogeneic HCT is the introduction of less intense regimens as an alternative to the standard myeloablative regimens, and improved post-transplant support ${ }^{6,7}$.

Allogeneic HCT can achieve the goal of curing disease by one of two approaches. The first approach utilizes high doses of chemotherapy with or without radiation in order to eradicate tumor cells, afterwards the patient is infused with stem cells from a donor. The second approach utilizes the GVT effect discussed earlier to eradicate tumor by relying on 
the immune response mediated by donor cells in response to foreign antigen present on the tumor cells.

Historically myeloablative regimens were the first conditioning regimens available to the clinician, however they were associated with high toxicities owing to the high doses of chemotherapy/radiation involved, leading to significant mortality and morbidity. The high mortality/morbidity associated with myeloablative conditioning regimens meant that only a small subset of patients had the ability to endure treatment, leading to the exclusion of many elderly patients with co-morbidities. The ability to rely on the GVT effect, allowed previously excluded patients to receive care by introducing less intense regimens (known as non myeloablative or reduced intensity).

\subsection{Immune reconstitution following allogeneic transplantation}

Immune reconstitution is a complex process involving the restoration of different types of immune cells including neutrophils, NK cells, T cells and B cells. Dysregulation of one compartment of immune cells has the ability to affect the normal development of other compartments. The innate immune system is the first to recover within weeks of transplantation, among the cells to first recover are neutrophils of myeloid origin, and NK cells of lymphoid origin ${ }^{2,8}$. A major role of innate immunity is to recognize pathogens without the need of priming or presentation of antigen, unlike adaptive immunity, allowing 
for a fast response that is critical for prevention of infection. In addition to the NK cells being the first lymphocyte subset to recover they also play a role in the recognition and eradication of tumor cells and virally infected cells ${ }^{9}$.

Adaptive immunity takes much longer to be restored and follows a more gradual road to recovery. Compared to the innate immune system, adaptive immunity is able to eliminate infections more efficiently by providing an antigen specific response. Dysregulation of adaptive immunity as noted previously does not only render the host more susceptible to infections but also predisposes the patient to other conditions including GVHD and disease relapse. Both T cells and B cells reconstitute at a much slower rate than the other immune cell compartments and may take years to fully recover.

Generally T cell development does not follow a normal course of development post transplantation, and primarily depends on $\mathrm{T}$ cell expansion of mature donor cells, with $\mathrm{T}$ cell neogenisis occurring much later in part owed to the thymic dysfunction ${ }^{2,9}$. The $\mathrm{CD}^{+}{ }^{+}$ $\mathrm{CD}^{+}$ratio was also found to be inverted, due to a faster reconstitution of $\mathrm{CD} 8^{+} \mathrm{T}$ cells approximately taking 3-4 months, while $\mathrm{CD}^{+} \mathrm{T}$ cells generally take about 6-12 months ${ }^{2}$. Thymic function plays a large role in $\mathrm{T}$ cell regeneration and consequently the ability of the immune system to produce a competent diverse repertoire. A decrease in thymic function has been attributed to older age, aGVHD, and intensive conditioning regimens 10,11 
B cell reconstitution on the other hand follows a normal course of development, with antigen naïve B cells first appearing followed by memory B cells taking 1-2 years to achieve normal numbers ${ }^{9}$. Many studies looked at immune reconstitution in total numbers, including Maris et al. who compared two groups of patients, one group receiving a nonmyeloablative regimen $(n=51)$ and the other group receiving a myeloablative regimen $(n=67)$ and had found that there was no difference in B cell count except on day 80 when the non-myeloablative recipients were found to have higher total B cells, it was thought to be in part to the fact that the non-myeloablative patients developed GVHD later and subsequently received treatment for GVHD later in the transplant course leading to this variation ${ }^{12}$. Petersen et al. compared two myeloablative groups, with a non-myeloablative group and found B cell counts were significantly reduced in the non-myeloablative group at 120 days post-transplant ${ }^{13}$. Schulenburg et al had found B cell recovery reached normal by one year in the myeloablative regimens and reconstituted at a faster rate when compared to the non-myeloablative regimen ${ }^{14}$. Other studies found that there was no difference in B cell counts when comparing myeloablative vs. non-myeloablative ${ }^{5,15,16}$. A more recent study comparing reconstitution following different conditioning regimens in our lab by Jacobson et al. showed that significant differences were found with regards to BAFF levels between the myeloablative and non myeloablative group. When total B cell recovery was looked at there was no significant difference between the different groups with regards to total B cell numbers (analysis of different B cell subsets was not available) ${ }^{17}$. 
Another important factor is the close and dependent relationship of $\mathrm{B}$ cells with $\mathrm{T}$ cells. The delayed reconstitution of CD4 $\mathrm{T}$ cells can have a direct effect on the development of $\mathrm{T}$ cell dependent memory B cells leading to severe dysregulation. Recent evidence has shown that not only the skin, liver and GI are significantly impacted by aGVHD but also the thymus and bone marrow may be affected delaying reconstitution of both $\mathrm{T}$ cells and B cells, leading to prolonged lymphopenia and subsequently $\mathrm{T}$ cell/B cell dysfunction ${ }^{18-}$ 20.

Overall within the literature there have been contradictory findings with regards to reconstitution with the recognition that evaluation of immune dysregulation involves not only total numbers, but requires one to consider the type/quality of immune cell subset recovery.

\section{$\underline{3.3 \text { B cells }}$}

B cells are responsible for the mediation of humoral immune responses and express on their surface antigen specific immunoglobulin receptors. The recognition of antigens in the presence of cytokines and co-stimulation (provided by $\mathrm{CD}^{+} \mathrm{T}$ cells), lead to the proliferation of antigen specific cells (clonal expansion) committed to plasma cell differentiation. The natural development of B cells takes place in two major phases. 
The first phase is initiated in the bone marrow where B cell precursors differentiate into mature B cells under the influence of cytokines and stromal interaction. Once B cells become mature they are released into the peripheral blood. Prior to release into the periphery B cells within the bone marrow undergo a selection process known as central tolerance. Central tolerance allows the exclusion of autoreactive B cells expressing B cell receptors $(\mathrm{BCR})$ that strongly interact with self-antigens by deletion, receptor editing or inactivation (anergy) ${ }^{21,22}$. The role of central tolerance in preventing the release of autoreactive B cells, is not always successful and a proportion of B cells released into the periphery continue to be autoreactive ${ }^{23}$.

The second phase once in the peripheral blood B cells migrate to secondary lymphoid organs and mature into memory and effector cells. The formation of memory B cells may occur through the more common and widely known $\mathrm{T}$ cell dependent pathway or the less common pathway, independent of $\mathrm{T}$ cells. $\mathrm{T}$ cell dependent processes occur within lymphoid organs when $\mathrm{B}$ cells experience antigen and interact with $\mathrm{T}$ cells leading to the formation of germinal centers. Within the germinal center B cells in the dark zone proliferate, and diversify BCR's through a process known as somatic hyper mutation (SHM). In the light zone affinity maturation occurs where B cells compete for antigen, and B cells with high affinity BCR's are selected for survival and become memory B cells and plasmablasts that will go on to become plasma cells. B cells also undergo class switch recombination (CSR) within the GC. ${ }^{21,22}$. 


\section{$\underline{\text { 3.3.1 B cells and GVT }}$}

While the role of donor T cells and NK cells have been extensively studied, indicating that both have a role as mediators of GVT, the need for more studies evaluating B cells is needed. B cells may act as mediators of tumor suppression through antibody dependent cellular cytotoxicity processes or as antigen presenting cells (APC), presenting antigen to $\mathrm{T}$ cells, and enhancing $\mathrm{T}$ cell activation/response ${ }^{2}$. Two consecutive studies by Miklos et al. gave some insight into the GVT effect of B cells, the first looked at 150 patients and showed that $50 \%$ of male recipients having female donors developed antibodies to DBY proteins, while the second study looked at 75 patients and further identified 5 more antibodies to different HY proteins ${ }^{24,25}$. In the second study patients with HY antibodies did not relapse while $48 \%$ of patients without $\mathrm{HY}$ antibodies relapsed. Other studies have also identified tumor associated antigens like the B cell maturation antigen (BCMA) eliciting an antibody response after transplant for multiple myeloma patients receiving donor lymphocyte infusions (DLI) ${ }^{26,27}$.

\subsubsection{B cells and cGVHD}

Clinically cGVHD presents as other autoimmune diseases, such as lupus and rheumatoid arthritis, but the exact pathogenesis of cGVHD is still not understood. This is compounded by the fact that there are no animal models available that may represent 
cGVHD in its entirety, to be used in preclinical studies ${ }^{4,28}$. cGVHD has an incidence of $30-65 \%$ and remains to be the leading cause of non-relapse mortality ${ }^{29,30}$.

The pathophysiology of cGVHD is thought to be primarily mediated by donor T lymphocytes expanding and unchecked, by a dysfunctional central/peripheral tolerance mechanism, leading to organ damage ${ }^{31}$. Further research and better understanding of cGVHD pathobiology has led to evidence that B cells and dendritic cells may also play a critical role in the pathogenesis and maintenance of cGVHD ${ }^{4,24,32}$.

Other factors that may affect and/or play a role in the development of cGVHD include a) Graft composition, where it has been shown that the incidence of cGVHD varies when umbilical cord transplants, bone marrow transplants, and peripheral blood stem cell transplants are compared ${ }^{33-36}$, b) Graft manipulation and depletion of T-cells ${ }^{37,38}$, c) Older age patients ${ }^{38,39}$, d) Female donors to male recipients because of lymphocyte response to minor histocompatibility antigens found on the $\mathrm{Y}$ chromosome ${ }^{4,40}$, e) Donor lymphocyte infusions $\left.(\mathrm{DLI})^{38}, \mathrm{f}\right)$ The type of preparative regimen non-myeloablative vs. myeloablative 17.

Overall evidence supports the fact that B cells play a role in the development and clinical manifestation of cGVHD ${ }^{4}$. B cells are professional antigen presenting cells (APC) providing co-stimulatory molecules and priming of $\mathrm{T}$ cells to minor histocompatibility antigens (miHA). The role of B cells is further supported as evidenced in clinical trials 
incorporating B cell depletion therapy (rituximab), leading to a lower overall incidence of both cGVHD and steroid requiring cGVHD ${ }^{32,41-43}$.

Evidence has also shown that B cell homeostasis is altered, leading to increased B cell activating factor $(\mathrm{BAFF}) / \mathrm{B}$ cell ratios in patients with $\mathrm{cGVHD}$ when compared to patients without cGVHD and healthy donors ${ }^{44}$. High concentrations of BAFF can promote auto reactive B cell survival, not only playing a role in other autoimmune diseases but also correlated with an increased incidence of cGVHD ${ }^{45,46}$. The role of B cells, in addition to acting as acting APC's, is the production of auto-antibodies leading to disease progression. B cell antibody responses to miHA correlated with cGVHD progression or remission as indicated in the study previously mentioned by Miklos et al. in which a positive correlation between the presence of antibodies to HY proteins and the development of cGVHD was found ${ }^{24}$.

It has been thus far shown that B cells play a dual role in the pathogenesis of cGVHD by acting as APC and producing antibodies. A third role by a group of B cells identified as regulatory B cells may play a vital role in regulating immune responses ${ }^{47,48}$. $\mathrm{B}$ regulatory cells (B reg) have only recently been identified over the past decade, and have the capability of producing IL-10 an anti-inflammatory cytokine. B reg cells were found to be enriched in multiple subsets including transitional B cells, $\operatorname{IgM}$ memory B cells and, plasmablast subsets with recent studies showing that patients with cGVHD were found to be deficient in B reg cells ${ }^{49,50}$. The continued study of B cell subsets whether conventional 
or regulatory in patients presenting with cGVHD may lead to further essential insight into the pathophysiology and treatment of cGVHD.

\subsubsection{B cells and infection}

Infection following allogeneic transplantation still remains a cause of mortality/morbidity. Immune reconstitution as discussed previously reconstitutes at different rates for different compartments. The early post-transplant period (within the first 30 days) poses the greatest risk to bacterial, fungal and viral infections, as all compartments of the immune system are compromised (pancytopenia) in addition to barrier breakdown. Later increased susceptibility to infections remains up to one year because of both lymphopenia and dysfunction of both $\mathrm{T}$ cells and $\mathrm{B}$ cells, in addition to GVHD prophylaxis/treatment. The lack and dysfunction of lymphocytes including memory B cells, renders patients susceptible to infections caused by encapsulated bacteria, such as Haemophilus influenza, fungal infections such as aspergillus and Pneumocystis jiroveci and, viral infections including CMV and VZV ${ }^{51,52}$. When myeloablative conditioning regimens were compared to non-myeloablative conditioning regimens it was found that the myeloablative group were significantly at an increased risk of developing infections, this may in part be due to the fact that irradiation based regimens are considered a risk factor especially for late severe bacterial infections ${ }^{14,53}$. A study found that only B cells were 
linked to late infections in disease free patients post-transplant at both 1 and 2 year time points 54

\section{$\underline{3.4 \mathrm{~B} \text { cell phenotypes }}$}

It is clear from the collective findings of previous studies that B cell immune reconstitution should be studied not only quantitatively but qualitatively, and that characterization of $\mathrm{B}$ cell defects following allogeneic HCT can provide insight into advancing our understanding of immune reconstitution and mechanisms. Furthermore, these results may guide future therapy considerations reducing morbidity and mortality and improving overall treatment outcomes.

Mature B cells can be divided into two major groups, antigen naïve CD27-and, antigen experienced CD27+ and then further subsets can be identified (Table 1).

\subsubsection{CD19+ and CD20+}

All peripheral blood B cells express the surface proteins CD19 and CD20 in all stages of maturation/development except in the final stage (plasma cells). CD19 is a protein and forms a co-receptor complex with CD21 and CD81 to synergistically act with BCR's to the activation of B cells. CD20 one of the earliest B cell specific surface proteins to be 
recognized, regulates the transportation of calcium, and is thought to play a role in the activation of B cells especially in $\mathrm{T}$ cell independent responses ${ }^{55}$. Total B cell recovery may vary quantitatively at different time points and when tracking recovery similar results were observed when using either marker ${ }^{56}$.

\subsubsection{CD19+CD27- and CD19+CD27+}

CD27 is a protein member of the tumor necrosis factor receptor family and is expressed on both T and B cells. Antigen naive B cells that have not encountered antigen do not express the surface protein CD27 and are typically identified by CD19+CD27-. B cells are committed to become plasma cells once they encounter antigen and express CD27 and may be identified by CD19+CD27+. Using CD27 as marker of memory allowed the identification and separation of antigen naïve subsets from antigen experienced subsets ${ }^{57}$. The importance of $\mathrm{CD} 27+$ has been shown in previous studies as evidenced in the identification of B cells that were previously misclassified into antigen naïve subsets ${ }^{58}$.

\section{$\underline{3.4 .3 \text { IgD vs. CD38 }}$}

$\mathrm{IgD}$ is expressed on mature $\mathrm{B}$ cells in the final transition from immature B cells. The exact process leading to the expression of $\operatorname{IgD}$ is not known, but is thought to play a role in B cell activation. In secondary lymphoid tissues when B cells are exposed to antigen and enter the germinal center $\operatorname{IgD}$ is down regulated ${ }^{59}$. 
CD38 is a surface glycoprotein found on most immune cells and plays a role in signal transduction leading to activation ${ }^{58,60}$. Loss of CD38 has been recognized to lead to impaired immune responses ${ }^{61}$.

Surface staining of $\operatorname{IgD}$ and $\mathrm{CD} 38$ was first used to identify different developmental stages of B cells from naïve to final stage memory B cells in secondary lymphoid tissues known as the BM1-BM5 classification system. Studies utilizing CD27 in combination with $\operatorname{IgD}$ and $\mathrm{CD} 38$ found that the limitation of this classification system was overcome and allowed the identification of different developmental stages in peripheral blood (Table 1) $58,62$.

\section{$\underline{\text { 3.4.4 CD19+ CD27- IgD+ CD38+ B cells }}$}

Transitional B cells identified as CD19+ CD27- IgD+CD38+ are among the first $\mathrm{B}$ cells released from the bone marrow and are an important link between the bone marrow and periphery. It is thought that only $10-30 \%$ will have the ability to develop into naïve B cells and up to $20 \%$ are thought to be autoreactive ${ }^{23}$. The total amount of transitional B cells entering the periphery may vary under different circumstances (such as infection) and is thought to play an important role in overall regulation of B cell homeostasis. Dysregulation within this compartment may lead to an increased state in which autoreactive B cells (low affinity B cells) survive. 
Transitional B cells undergo a second important checkpoint in the periphery, in attempt to delete auto reactive B cells but little is known about the process by which transitional B cells become naïve B cells. In an attempt to avoid auto reactivity transitional B cells continue to express some amount of RAG and have the ability to internalize BCR's and undergo a process known as receptor revision ${ }^{63}$. Under normal circumstances transitional B cells are short-lived, and in a state of dysregulation elevated levels of BAFF are found to prolong survival, increasing the chances of low affinity B cells entering the naïve pool. It is also recognized that both BAFF and BCR stimulation are crucial for the transition into naïve B cells ${ }^{64,65}$.

\subsubsection{CD19+ CD27- IgD + CD38 low/- B cells}

Mature naïve B cells identified as CD19+ CD27- IgD + CD38 low/- circulate between lymph nodes in search of antigen. Naïve B cells express the receptor CXCR5 specific for chemokines that are found in abundance in follicles, facilitating their entry. Once B cells encounter antigen within the follicle the surface receptor CCR7 is upregulated and promotes the migration of $\mathrm{B}$ cells to the T-B border. Two paths are undertaken by B cells after interaction with $\mathrm{T}$ cells, one leading to the formation of a GC (further discussed in section 3.4.8), and the second leads to an extra-cellular focus in which plasmablasts are formed with low affinity antibodies (further discussed in section 3.4.9) ${ }^{66}$. The exact process leading to which pathway is chosen is not clearly defined, but It is thought that the 
up regulation or down regulation of specific receptors may decide which pathway is chosen, including the up regulation of CXCR4 favoring the germinal center pathway or up regulation of EBI2 favoring plasmablast formation ${ }^{67}$. Furthermore CCR7 is highly expressed on naïve B cells, but is not expressed on plasmablasts, allowing plasmablasts to escape the chemokine gradient within lymphnodes ${ }^{68,69}$.

\section{$\underline{\text { 3.4.6 CD19+ CD27+ IgD+ CD38 low/- B cells }}$}

IgD memory B cells identified as CD19+ CD27+ IgD+CD38 low/- are a distinct subset of mostly un-mutated class B cells that are found in the periphery with the ability to produce $\operatorname{IgM}{ }^{70,71}$. Evidence as to the source of un-mutated $\operatorname{IgD}$ memory B cells is unclear and evidence both for and against development in the GC have been proposed. It is thought that if they are $\mathrm{GC}$ derived they prematurely escape the GC before CSR takes place forming the $\mathrm{IgD}$ memory pool ${ }^{71}$. The second proposition is that they may arise independently from the GC and may arise from the outer follicle (the same type of cells that give rise to the extra follicular foci plasmablasts giving rise to the $\operatorname{IgD}$ memory B cells) ${ }^{72}$. Alternatively IgD memory B cells may arise from both pathways ${ }^{21}$.

\section{$\underline{\text { 3.4.7 CD19+ CD27+ IgD+ CD38+ B cells }}$}


Pre germinal B cells are identified as CD19+ CD27+ IgD + CD38+. After B cells encounter antigen in the follicle, and interact with $\mathrm{T}$ cells at the T-B border, they will reenter the follicle as pre-germinal cells (germinal founder). Prior to reentering and establishing the germinal center it is proposed that these cells may expand in extra follicular regions, allowing the production of a sufficient number of clonal B cells, able to endure the rigorous process within the germinal center ${ }^{66}$. The expression of BCL- 6 (transcription factor) is essential for germinal center formation and is expressed on pre germinal B cells. B cells committed to extra follicular plasmablast formation do not express BCL-6 ${ }^{67}$.

\section{$\underline{\text { 3.4.8 CD19+ CD27+ IgD low/- CD38 low/- B cells }}$}

Post germinal memory B cells are identified as CD19+ CD27+ IgD low/- CD38 low/-. Once B cells enter the GC two compartments known as the dark and light zone are formed. B cells proliferating within the dark zone are known as centroblasts and undergo a process known as somatic hyper mutation (SHM) by down regulating surface immunoglobulin and activation of the AID enzyme. Once the B cells re-express immunoglobulin they enter the light zone as centrocytes and compete for limited antigen presented on follicular dendritic and $\mathrm{T}$ helper cells. B cells with high affinity BCRs are able to capture the most antigen and are capable of forming the most MHC-II complexes with $\mathrm{T}$ follicular helper cells $(\mathrm{T}$ fh). In turn $\mathrm{T}$ fh cells provide co-stimulatory signals critical for B cell survival. Chemokines within the GC are responsible for cycling between the dark 
and light zone, and lead to multiple rounds of proliferation and selection, a process critical for affinity maturation. Eventually centrocytes differentiate into memory B cells or plasma cells and leave the GC. Not all centrocytes survive and the ones without high affinity for antigen or auto reactivity undergo cell death by apoptosis ${ }^{63,67,73,74}$. CSR also occurs in the GC and is also activated by AID the same enzyme responsible for SHM but only the constant region of the immunoglobulin is changed allowing antigen specificity to be unaffected.

\section{$\underline{\text { 3.4.9 CD19+ CD27+ IgD low/- CD38+ plasmablasts }}$}

Plasmablasts are identified as CD19+ $\mathrm{CD} 27+\mathrm{IgD}$ low/- CD38+ and are immature plasma cells. Plasmablasts still have the ability to proliferate unlike plasma cells. As previously discussed $\mathrm{B}$ cells in secondary lymphnode organs may differentiate into plasmablasts by one of two pathways. The first and classical pathway involves GC maturation leading to high affinity antibodies. The second pathway is less recognized and involves the direct migration of activated B cells from the T-B border into extra-follicular niches, providing a relatively rapid antigen specific response but have not undertaken affinity maturation as their counterparts in the $\mathrm{GC}^{67}$. 


\subsection{Hypothesis and Specific Aim}

We hypothesized that aberrant maturation of B cells will persist even when quantitative B cell recovery has been achieved.

Aim: Quantify B cell recovery after HCT and determine phenotypic abnormalities of peripheral B cell maturation in a large cohort of adult patients.

Prospectively obtain blood samples from normal patients and patients receiving preparative myeloablative or reduced intensity conditioning regimens prior to allogeneic HCT. Samples obtained at 1, 2, 3, 6, 12, 18, 24, 30, and 36 months after transplantation. Absolute numbers of B lymphocyte subsets for each group will be obtained by flow cytometry. 


\section{$\underline{5.0 \text { Study Design and methods }}$}

\subsection{Patient characteristics}

399 patients (91 receiving Myeloablative conditioning, and 308 patients receiving reduced intensity conditioning) treated with allogeneic HCT at the Dana-Farber Cancer institute and Brigham and Women's Hospital between January 2007 and January 2014 were enrolled. In addition single blood samples of 19 normal healthy donors (HD) were included in this study. All subjects were enrolled in clinical research protocols 764 and 855 (details provided in section 5.1.3) and written informed consent was obtained.

\subsubsection{Inclusion criteria}

1. Patients who have undergone allogeneic HCT (for patients that undergo more than one transplant only samples after the latest transplant will be included).

2. Patients surviving at least 30 days post-transplant.

3. Patients with hematological malignancies/disorders.

\subsubsection{Exclusion criteria}

1. Patients receiving monoclonal antibody treatment effecting immune reconstitution e.g. Rituximab. 
2. Umbilical cord grafts because of different immune reconstitution.

3. Pretreated grafts e.g. T-cell depleted grafts may have an effect on the development of immune reconstitution and delay certain B-cell subsets.

4. Time points after transplantation taken for relapsed patients will not be included.

\subsubsection{Preparative regimens}

All patients received myeloablative or reduced intensity conditioning according to treatment plan 764 and 855 (Table 2 and 3).

Treatment plan 764 (myeloablative)

1. Cyclophosphamide $1800 \mathrm{mg} / \mathrm{m}^{2}$ IV QD days -6 and -5

2. Total body irradiation (TBI) days $-4,-3,-2,-1$

Treatment plan 855 (reduced intensity)

1. Fludarabine $30 \mathrm{mg} / \mathrm{m} 2 \mathrm{IV}$ QD, days $-5,-4,-3,-2$.

2. Busulfan $0.8 \mathrm{mg} / \mathrm{kg}$ IV days $-5,-4,-3,-2$.

\subsection{Sample collection}

Whole blood obtained in 15\% EDTA-containing collection tubes was collected prospectively at $1,2,3,6,12,18,24,30$, and 36 months. Samples utilized were obtained 
from patients who had consented to provide blood for research purposes as part of a Dana Farber Institutional Review Board-approved protocol.

\section{$\underline{5.3 \text { Sample preparation }}$}

Round bottom tubes of $50 \mathrm{uL}$ of fresh whole blood were incubated with fluorophore-conjugated monoclonal antibodies specific for CD5, CD19, CD20, CD27, CD38, CD45, IgD and BAFF-R (table 4) for 10 minutes. 500 uL PharmLyse lysing solution was then added to lyse RBC's and left for another 15 minutes before running on flow cytometer.

\subsection{Flow cytometer analysis}

Blood samples were run in a BD FACS Canto II flow cytometer (Beckman Coulter Inc., Brea, California). Color detectors are able to recognize the colors of light emitted by fluorochromes attached to corresponding surface markers. The data was then collected and analyzed using FlowJo software (Tree Star).

Forward (FSC) and side (SSC) scatter was used to establish and gate the lymphocyte population. To improve lymphocyte purity, and reduce the number of contaminants, we then gated CD45 vs SSC for all future gates ${ }^{75}$. Within the CD45 
population a CD20 vs SSC dot plot was used to gate total B cells for B cell recovery. We then gated for antigen naïve (CD19+CD27-) and antigen experienced (CD19+CD27+) B cells from within the CD45 population using a CD19 vs. CD27 dot plot (Fig 1). For both the antigen naïve and antigen experienced populations we used an IgD vs. CD38 dot plot to obtain the remaining subsets (Fig 2 and 3). 


\section{$\underline{6.0 \text { Statistical analysis }}$}

Patient baseline and transplant characteristics and GVHD were reported descriptively, and compared using the Fisher exact test, Chi-squared test or Wilcoxon rank sum test. B cell data were analyzed descriptively at each time point and compared using the Wilcoxon rank sum test. All $\mathrm{P}$ values are 2 sided at the significance level of 0.05 for baseline characteristics and 0.01 for comparisons of B cells. Multiple comparisons were considered in B cell comparisons. The Kaplan-Meier method was used to estimate overall survival (OS) and progression-free survival (PFS). OS was calculated from the date of transplantation to the date of death. PFS was calculated from the date of transplantation to the time of relapse/disease progression or death, whichever occurred first. All calculations were performed using SAS 9.2 (SAS Institute, Cary, NC) and R 2.10.1. 


\section{$\underline{7.0 \text { Results }}$}

\section{$\underline{7.1 \text { Patients }}$}

399 patients were enrolled in this study. 224 males (56.1\%) and 175 females (43.9\%) with a median age of 58 years (range 19-74) for all patients. The 2 year overall survival was $65 \%$ and the 2 year progression free survival was $55 \%$. The most common primary diagnosis was AML (35.1\%), followed by MDS (17\%), and NHL (13.8\%). For 227 patients (56.9\%) donor was of the same gender as recipient, 74 male patients (18.5\%) had female donors, and 98 female patients $(24.6 \%)$ had male donors. The majority of patients received PBSC $(93.7 \%$ ), with 23 receiving bone marrow grafts and 2 received both PBSC and bone marrow. HLA typing was matched for 367 patients (122 related and 245 unrelated) and the remaining 32 patients received mismatched transplants. Tacrolimus, Sirolimus, methotrexate and mycophenolate mofetil were provided as part of a two or three GVHD prophylaxis regimen. 308 patients (77.2\%) received reduced intensity conditioning regimen (RIC) and 91 (22.8\%) received myeloablative conditioning (MAC) (Table 5).

\subsection{B cell reconstitution}

\section{$\underline{\text { 7.2.1 Total B cell recovery }}$}


Analysis of total B cell recovery (CD20+) compared to HD was carried out for all time points post HCT for the three year period. B cell Lymphopenia was characteristic of the first year following transplant as expected. The absolute number of total B-lymphocyte counts were exceedingly low for time points 1,2 and 3 months post HCT $\left(4.9 \times 10^{6} / \mathrm{L} ; 11.2\right.$ x $10^{6} / \mathrm{L}$; and $19.6 \times 10^{6} / \mathrm{L}$ respectively). Although a gradual increase was noted, absolute numbers when compared to HD remained low until month $9\left(118.8 \times 10^{6} / \mathrm{L}\right.$ vs $204 \times 10^{6} / \mathrm{L}$, $\mathrm{P}<0.02)$ and normal levels were reached by month $12\left(151.7 \times 10^{6} / \mathrm{L}\right.$ vs $204 \times 10^{6} / \mathrm{L}, \mathrm{P}<$ 0.21). Elevated levels were noted for remaining time points but did not reach significance (Table. 6 and Fig. 4).

Gating of CD27 expression allowed us to identify antigen experienced B cells. Absolute numbers $\left(15.9 \times 10^{6} / \mathrm{L}\right.$ vs $55.2 \times 10^{6} / \mathrm{L}$; Table 7 and Fig. 5$)$ and frequency $(0.8 \%$ vs 3.30\%; Table 8 and Fig. 6) of antigen experienced B cells was highest at 36 month post HCT but when compared to HD levels all time points post HCT remained below normal $(\mathrm{P}<0.0001)$. Although total B cells did reach normal levels we found that recovery was primarily due to the antigen naïve B cell compartment for all time points post HCT (Table 9 and Fig. 7).

\subsubsection{Antigen Naïve B cells and subsets}

Within the antigen Naïve compartment, we looked at the recovery profile of both transitional and naïve B cells. We found that at month 2 post HCT there was a surge in 
transitional B cells with elevated frequencies $(29.40 \%$ vs. $7.5 \%$; $<0.0001)$ until month 9 post HCT $(12.5 \%$ VS 7.5\%; $\mathrm{P}<0.02)$, and reaching normal frequencies by month 12 (10.9\% VS 7.5\%) when compared to HD (Table 10).

Naïve B cells post HCT were below normal frequencies at month $2(52.2 \%$ vs $87.2 \%)$ month $3(68.10 \%$ vs $87.2 \%)$ and month $6(73 \%$ vs $87.2 \%)$ post HCT when compared to HD $(\mathrm{P}<0.0001)$. Normal frequencies were achieved at month $9(82.5 \% \mathrm{vs}$ 87.2\%) (Table 11).

The rise in naïve B cells was inversely proportional to transitional B cells showing a disproportionate recovery of antigen naïve B cells until homeostasis was achieved by month 12 (Fig. 8 and 9).

\subsubsection{Antigen experienced B cells and subsets}

Absolute numbers of the total antigen experienced B cell compartment was extremely low for the first 3 months post HCT (Table 7) and gating of populations due to few events may not have been a true representation of recovery leading us to exclude time points 1,2 and 3 post HCT when interpreting relevance for all memory subsets. The 4 subsets identified by plotting IgD vs CD38 within the antigen experienced compartment (CD27+) are the IgD memory B cells (CD19+ $\mathrm{CD} 27+\operatorname{IgD}+\mathrm{CD} 38$ low/-), pre-germinal center B cells also known as germinal founder cells (CD19+ CD27+ IgD + CD38+), class switched post-germinal memory B cells 
(CD19+ CD27+ IgD low/- CD38 low/-) and plasmablasts (CD19+ CD27+ IgD low/$\mathrm{CD} 38+)$.

Recovery of the IgD memory B cell subset remained below normal frequency for most time points when compared to HD (Table 12 and Fig. 10). This subset includes IgD memory B cells that have a mutated $\mathrm{V}$ region after passing through the $\mathrm{GC}^{58}$.

Pre germinal center B cells were found to have a significantly elevated frequency starting from month $6(4.80 \% \mathrm{VS} 0.70 \% ; \mathrm{P}<0.0002)$ post $\mathrm{HCT}$, and remained elevated for the duration of this study when compared to HD for all time points (Table 13 and Fig 11).

The post germinal class switched memory B cells were below normal frequencies for month 6,9 and 12 post $\mathrm{HCT}(40 \%, 37.9 \%$, and $45.9 \%$ vs $54.9 \%)$. Normal frequencies were achieved at month $18(51.6 \%$ vs $54.9 \%)$ and continued for the duration of this study until month 36 (58.70\% vs 54.9) post HCT (Table. 14 and Fig. 12)

Frequency of plasmablasts were significantly elevated from month $6(7.3 \% \mathrm{vs}$ $1.1 \%$; $\mathrm{P}<0.0009)$ post HCT to month $36(6.7 \%$ vs $1.1 \%$; $\mathrm{P}<0.0001)$ post HCT (Table. 15 and Fig. 13)

\subsubsection{Myeloablative conditioning vs reduced intensity conditioning}

Finally we compared the two different conditioning regimens MAC vs RIC to identify differences in reconstitution. We found that $\mathrm{B}$ cells reconstituted at a faster rate in 
the MAC group (Table 16 and Fig. 14) reaching normal levels compared to HD at month 12 post HCT $\left(203.1 \times 10^{6} / \mathrm{L}\right)$ and the RIC group reaching normal levels at month 18 post HCT $\left(189.7 \times 10^{6} / \mathrm{L}\right)$. Absolute numbers for the antigen experienced B cells reconstituted at a faster rate in the MAC group but remained below normal levels when compared to HD for the duration of the study (Table 17 and Fig. 15). Looking at frequency profiles within the antigen naïve compartment we found significant differences for frequencies of transitional B cells MAC vs RIC at month 2, 6, 12 and 18 post HCT (35.9\% vs 28.39\%; $24.7 \%$ vs $19.7 \% ; 12.9 \%$ vs $9 \%$ and $10.9 \%$ vs $7.3 \% ; \mathrm{P}<0.05)$ with elevated levels in the MAC group compared to the RIC group (Table 18 and Fig. 16). Naive B cell differences were significant for month 2, 12, 18 and 36 post HCT $(36.7 \%$ vs $54.5 \%$; $81.8 \%$ vs 87\%; $85.3 \%$ vs $88.8 \% ; 80.10$ vs $89 \% ; \mathrm{P}<0.05)$ with RIC recovering to HD levels at a faster rate (Table 18 and Fig. 17).

Frequencies of pre germinal and post germinal B cells within the antigen experienced compartment did not differ for the duration of the study (Table 18 and Figs. 18 and 19). IgD memory B cells were increased at time points 12,18 and 36 post HCT $(29.2 \%$ vs $34.3 \%$; $29 \%$ vs $34 \% ; 16 \%$ vs $30.7 \%$; $\mathrm{P}<0.05)$ for RIC when compared to the MAC group (Table 18 and Fig. 20). A single time point for plasmablasts was significantly elevated for the MAC group at time point 6 month post HCT $(12.5 \%$ vs $5.90 \%$; $<<0.05)$ when compared to the RIC group (Table 18 and Fig. 21). 


\section{$\underline{\text { 8.0 Discussion }}$}

A long lasting immunity requires the engraftment of hematopoietic cells and differentiation into functionally capable immune cells. The immune system is complicated in that many stages are involved in the development of a diverse immune repertoire and at times require the support of other cells in achieving that maturation. The B cell compartment has been reported in the literature mostly with regards to total numbers (quantitatively) and usually as part of a study with a focus on other major immune compartments for example, T cells and NK cells. Qualitatively there has been less research when it comes to B cells, and at times only one or two subsets are investigated and over a short time period. We look at B cell immune reconstitution for multiple subsets within the antigen naïve and experienced compartments for a large cohort of patients over a three year period.

Early in the post HCT period B cells typically have a slow recovery and a percentage of B cells are transferred with the graft, however once engraftment occurs B cells generally follow a normal ontogeny post $\mathrm{HCT}^{2,8,76}$. Normal total B cell recovery was achieved by 12 months post HCT. Interestingly we found that absolute numbers of experienced B cells never reached normal throughout the study $(\mathrm{p}<0.0001)$, and total absolute B cell recovery was primarily due to the antigen naïve compartment. This may be an Indication that bone marrow (central compartment) gradually returned to a state of normal production, and repopulation of peripheral blood was primarily by way of low affinity CD27- B cells, and on the other hand the peripheral compartment and matured CD27+ B cells remained compromised for prolonged periods. This was found to be true for both MAC and RIC regimens although quantitative recovery was achieved at a faster 
rate in the MAC regimen (12 month post HCT) when compared to the RIC regimen (18 month post HCT). This delay in reconstitution likely leaves RIC patients at an added disadvantage when compared to MAC.

Transitional B cells are among the first B cells to appear in the peripheral blood with highest frequencies at month 2 post HCT, followed by a progressive decline, returning to normal frequency at month 12 post HCT. A study looking at transitional B cells in 15 pediatric patients post HCT also noted that the first 3 months post HCT were characterized by a surge of transitional B cells ${ }^{77}$. Transitional B cells are important regulators of B cell homeostasis and are a key target of BAFF, a ligand that has the ability to provide signals through corresponding receptors, such as BAFF-R and BCMA (B cell maturation antigen) favoring proliferation, prolonging survival, and facilitating the maturation of transitional B cells into mature naïve B cells ${ }^{78,79}$. It is thought that transitional B cells may also have the capability of providing rapid antibody responses through $\mathrm{T}$ cell independent pathways after exposure to certain antigens, such as lipopolysaccharides ${ }^{22,80}$.

In $\mathrm{HCT}$ patients the combination of elevated levels of BAFF, increased frequencies of transitional B cells and lymphopenia may be critical in leading to a diseased state. Transitional B cells typically express low affinity BCR's and have the potential to be autoreactive, in the setting of lymphopenia there is reduced competition for BAFF, and normally deleted (negative selection) autoreactive transitional B cells are now able to survive and enter the naïve B cell compartment ${ }^{81}$. Further significance of transitional B 
cells and the potential role it may play in disease has been reported in the literature, a study by Greinix, H.T., et al. found that elevated proportions of transitional B cells and a decrease in memory B cells were associated with severe infections and cGVHD ${ }^{82}$. Other studies also found that elevated proportions of transitional B cells were present in SLE patients 83,84

We found that naïve B cell frequencies remained below normal and progressively returned to normal by month 9 post HCT. Recovery of transitional to naïve B cell frequencies were inversely proportional and antigen naïve B cells achieved normal ratios when compared to HD at month 12 post HCT. Naïve B cells have the ability to circulate in the periphery between lymphnodes in search of antigen and as transitional B cells, they continue to rely on BCR signaling and BAFF for survival. Under normal circumstances naïve B cells with relatively high affinity BCR's have a selective advantage in entering follicles and participating in $\mathrm{GC}$ reactions over autoreactive B cells ${ }^{79}$. A study by Cyster et al. found that in mice B cells competed for follicular space and exclusion of the autoreactive B cells from entering the follicle ensued ${ }^{85}$. Another study also involving murine models, found that the survival of auto-reactive B cell clones had been promoted in the setting of absent competition ${ }^{86}$. It is thought that $\mathrm{B}$ cells from within the naïve compartment may also produce low affinity memory B cells from $\mathrm{T}$ cell independent pathways, producing memory B cells that are phenotypically different and have not undergone affinity maturation like other class switched memory B cells ${ }^{87}$. Immune 
dysregulation can provide a setting in which autoreactive B cells are able to survive and enter the memory pool.

We then looked into the different antigen experienced subsets, and as mentioned previously total absolute numbers of antigen experienced B cells did not reach normal for the duration of this study. Furthermore we found multiple irregularities amongst the frequencies of the different antigen experienced subsets. First we found that IgD memory B cells remained below normal frequencies for the majority of the study period. The significance of low IgD memory B cells frequencies has been reported in autoimmune diseases. A study comparing healthy controls to SLE patients, found that IgD memory B cells were the only subset to be decreased in both remission and active disease states when compared to healthy controls. The level of reduction was also associated to the extent of elevated auto-antibody levels, implicating IgD memory B cells in the disease process ${ }^{88}$. In a more recent study similar findings was found in primary Sjögren syndrome patients where IgD memory B cells were found to be reduced and also inversely correlated to elevated autoantibody levels ${ }^{89}$. More studies would need to look into this relationship and clarify the possible role of $\operatorname{IgD}$ memory B cells leading to autoimmunity and perhaps cGVHD.

The next subset we looked into the pre germinal B cells was found to be significantly elevated for all time periods post HCT. Due to the low numbers/events and unclear representation in months 1-3 we only considered samples from month 6 post HCT 
onwards to be of significance. The importance of pre germinal B cells has been portrayed in a series of studies including a study by Sarantopoulos et al. who found that there was a negative correlation between BAFF and naïve B cell numbers in patients with cGVHD, but a positive correlation between BAFF, circulating pre germinal center B cells and plasmablast cells in cGVHD patients when compared to patients without cGVHD and normal healthy patients ${ }^{44}$. Arce, E et al found that in the setting of lymphopenia the predominant B cell subset in patients with systemic lupus erythematosus were found to be pre germinal center B cells ${ }^{90}$.

When we looked at the post germinal B cells we found frequencies were significantly below normal levels until month 12 post HCT. The first year post HCT is primarily characterized by defective GC formation, and explains the delayed reconstitution of post germinal B cells. This is further complicated owing to a shortage in helper cells such as CD4 $\mathrm{T}$ cells (including the $\mathrm{T}$ fh), and follicular dendritic cells required for GC reactions ${ }^{91}$. It is also of interest to point out that $\mathrm{T}$ fh by providing stimulatory signals, through cytokines (e.g. IL-21), CD40 and ICOS have a vital role in GC formation. The role of $\mathrm{T}$ fh in addition to forming/maintaining $\mathrm{GC}$ responses include promoting $\mathrm{B}$ cell proliferation, survival, affinity maturation and Ig class switching ${ }^{92-94}$. Recent evidence in murine models points to the potential role of $\mathrm{T}$ fh cells differentiating from allo-activated naïve $\mathrm{T}$ cells in cGVHD promoting high affinity antibodies capable of causing severe damage ${ }^{93}$. With respect to memory $\mathrm{B}$ cells and the role in immune mediated diseases a recent study found that patients with active rheumatoid arthritis had a significant increase 
of B memory cells when compared to those with low disease ${ }^{95}$ and a retrospective study of 98 patients found that patients with active cGVHD were associated with a lack of memory B cells with an increased susceptibility to infection ${ }^{96}$. Overall a competent post germinal B cell recovery leading to negative selection of poor affinity B cells and positive selection for a functionally diverse repertoire, is critical in preventing severe infections and autoimmunity.

The final subset we looked at were plasmablasts. Plasmablast frequencies were significantly elevated at month 6 post HCT and continued to be elevated for the remainder of the study (month 1-3 plasmablast levels were undetectable). Plasmablasts from extra follicular foci do not seem to have undergone SHM and affinity maturation and as a result produce low affinity antibodies ${ }^{72,97}$. A major function of plasmablasts is the ability to provide short-lived rapid responses, however in the presence of increased BAFF levels plasmablast survival is prolonged, and may be responsible in prolonging a defective response ${ }^{98}$. The role of BAFF in survival of plasmablasts may be a central factor in leading to a defective state of intolerance, contributing to disease. A study looking for B cell aberrations in SLE patients found that plasmablasts were 3 fold expanded when compared to healthy controls ${ }^{90}$ and another study also looking at SLE patients found that both proportion and number of plasmablasts were increased in active disease ${ }^{99}$. In cGVHD it was found that plasmablasts were increased in active disease when compared to healthy controls and patients without cGVHD ${ }^{44}$. 
Although B cell recovery occurred at a faster rate for the MAC group this may be attributed to the fact that all patients receiving RIC contained sirolimus until day 100 for GVHD prophylaxis in addition to the tacrolimus and methotrexate given to the MAC group. Jacobson et al. found that sirolimus may be associated with a delayed B cell recovery ${ }^{17}$. Total absolute antigen experienced B cells remained below normal levels for both MAC and RIC for the duration of this study, although the MAC group had a faster reconstitution of experienced B cells and may be a result of the increased total B cells available for maturation.

Even though MAC had a faster recovery of total absolute B cells and absolute antigen experienced B cells, most of the differences in frequency profiles were found among the antigen naïve subsets, and may be attributed to the role of the antigen naïve compartment as a major homeostasis regulator effected by a variety of factors including infection and disease ${ }^{78,79}$. In addition it is thought that transitional B cells are early immigrants and elevated premature release of B cells before complete maturation may indicate a disturbance in bone marrow, possibly due to a more intense regimen but further studies would need to be conducted. IgD memory B cells also found to be elevated at month 12, 18 and 36 post HCT are also believed to participate in rapid responses, and differences may be attributed to such a population being susceptible to different challenges and responses. Plasmablast frequencies were found to be significantly elevated at 6 month post HCT for the MAC group and this is the first time point taken after sirolimus was stopped for the RIC group. In addition the MAC group had higher incidences of aGVHD overall 
and this might be responsible for the increased rate of plasmablasts but further studies would need to be performed to identify causative factors.

The characterization of $\mathrm{B}$ cell reconstitution within different subsets of B cells allowed us to detect defects including elevated frequencies of low affinity transitional B cells, pre germinal cells and plasmablasts signifying a disturbed B cell homeostasis and loss of B cell tolerance. Elevated frequencies of B cells with low affinity BCR's is likely triggered by the ability to escape negative selection and the subsequent positive selection to produce allo and auto antibodies ${ }^{100}$. Autoreactive B cells also can act as APC's with the ability to present alloantigen to autoreactive CD4 $\mathrm{T}$ cells, augmenting activation and expansion of CD4 T cells increasing tissue damage ${ }^{100,101}$. It has also been proposed that $\mathrm{T}$ effector cell responses may be augmented by allo/auto antibody cross presentation of antigens in cGVHD ${ }^{102-104}$.

Sarantopoulos et al. discussed the potential of targeting subsets in established cGVHD, and it may also be tempting to target these pathways in an attempt to manipulate a favorable B cell reconstitution ${ }^{100}$. Several studies have identified specific autoreactive subsets within the transitional B cell compartment identified as CD21/Low that under normal circumstances are anergic, but in the presence of increased BAFF with increased signaling through the BCR pathway become activated, leading to a defective autoimmune state, associated with cGVHD and poor antimicrobial response ${ }^{82,105,106}$. Increased signaling through the BCR pathway was also found to promote elevated levels of both Syk 
and Btk (bruton's tyrosine kinase). Syk was noted to play an important role in the transition of transitional B cells into mature B cells, and mutations of the Syk gene can prevent entry of B cells into follicles ${ }^{107}$. Btk binds PLCG2 enzyme and is important in B cell maturation. Small molecule inhibitors of Syk and Btk are available, fostamatinib and ibrutinib, respectively and may be potential immune modifying agents with or without anti-BAFF treatment in attempt to obtain a favorable B cell homeostasis.

Pre germinal B cells express surface receptors TACI and BCMA (BAFF receptors) in high levels and are associated with spontaneous IgG production, mediation of disease, and poor antimicrobial responses ${ }^{44,108}$. These cells were found in cGVHD patients to be in a hyperactive state in the presence of elevated BAFF, leading to the activation of cell signaling molecules Akt and Erk, with a relative decrease in BIM (a pro apoptotic protein) 46,100. Plasmablasts also have the ability to spontaneously produce IgG, and survival of plasmablast is also prolonged in the presence of BAFF. Plasmablasts were found to also express CD20 in low levels compared to other B cells and may be a potential reason of persistence of this specific subset even after depletion by rituximab, leading to refractory cGVHD or recurrence in some cases ${ }^{109}$. Targeting BAFF as a potential target may mediate a favorable response in B cell reconstitution by diminishing BAFF mediated survival of low affinity B cells. Finally the identification of the bone marrow as being a potential target of aGVHD, and a delay of B cell recovery caused by destruction of bone marrow, may also be a target of intervention in an attempt to improve B cell lymphopoiesis but further studies are required ${ }^{19,20}$. 
Some of the limitations within this study is that we examined the immune reconstitution of only one class of immune cells, specifically B cells. Nevertheless characterization of B cell immune reconstitution both quantitatively and qualitatively, can provide further insight into patterns of reconstitution. We also were not able to analyze B reg cells in our study, mostly recognized in the literature by the functional capacity of IL10 production in addition to phenotypic characteristics. As previously noted B reg cells were found to be enriched in multiple B cell subsets complicating phenotypic identification and future studies looking into the B reg cell subset will require functional assay testing. Finally we did not obtain BAFF levels correlating increased BAFF levels and B cell aberrations. The importance of BAFF levels as previously discussed is also shown in studies looking at BAFF-R down regulation (in the presence of high levels of BAFF). De la Torre et al. found that BAFF-R expression was reduced in relapsed rheumatoid arthritis patients after rituximab therapy ${ }^{110}$. Sellam et al. found reduced BAFF-R expression on peripheral B cells of both primary Sjogren syndrome and systemic lupus erythematosus patients when compared to normal healthy patients ${ }^{111}$. 


\subsection{Conclusion}

Despite recovery of total B cells to normal levels in the first year post HCT, this period is characterized by an elevated frequency of transitional B cells and a reduced frequency of naïve B cells. Antigen experienced B cell subsets did not reach normal levels for the 3 year duration of this study. Within the antigen experienced compartment, increased frequencies of both pre germinal cells and plasmablasts were found in comparison to HD possibly due to premature escape from the germinal center before affinity maturation is completed giving rise to autoreactive lymphocytes.

This study highlights abnormal B cell recovery and maturation after HCT that persist for prolonged periods despite recovery of normal numbers of circulating B cells. Naïve and transitional B cells that predominate post HCT have low affinity BCRs and have been implicated in autoimmune diseases and chronic GVHD. Reduced numbers of high affinity antigen experienced B cells likely predispose patients to infectious complications post HCT. Better recognition of these disturbances may guide future therapeutic interventions restoring $\mathrm{B}$ cell homeostasis and targeting activation/survival pathways of pathogenic subsets. 


\section{$\underline{10.0 \text { References }}$}

1. Majhail NS, Douglas Rizzo J. Surviving the cure: long term followup of hematopoietic cell transplant recipients. Bone Marrow Transplant. 2013;48(9):1145-1151.

2. Wu CJ, Ritz J. Induction of tumor immunity following allogeneic stem cell transplantation. Adv Immunol. 2006;90:133-173.

3. van den Brink MR, Porter DL, Giralt S, et al. Relapse after allogeneic hematopoietic cell therapy. Biol Blood Marrow Transplant. 2010;16(1 Suppl):S138-145.

4. Socie G, Ritz J, Martin PJ. Current challenges in chronic graft-versus-host disease. Biol Blood Marrow Transplant. 2010;16(1 Suppl):S146-151.

5. Morecki S, Gelfand Y, Nagler A, et al. Immune reconstitution following allogeneic stem cell transplantation in recipients conditioned by low intensity vs myeloablative regimen. Bone Marrow Transplant. 2001;28(3):243-249.

6. Blaise D, Vey N, Faucher C, Mohty M. Current status of reduced-intensity-conditioning allogeneic stem cell transplantation for acute myeloid leukemia. Haematologica. 2007;92(4):533-541.

7. Mineishi S. Overcoming the age barrier in hematopoietic stem cell transplantation: progress, but still a long way to go. JAMA. 2011;306(17):1918-1920.

8. Bosch M, Khan FM, Storek J. Immune reconstitution after hematopoietic cell transplantation. Curr Opin Hematol. 2012;19(4):324-335.

9. Williams KM, Gress RE. Immune reconstitution and implications for immunotherapy following haematopoietic stem cell transplantation. Best Pract Res Clin Haematol. 2008;21(3):579-596. 
10. McIver Z, Melenhorst JJ, Wu C, et al. Donor lymphocyte count and thymic activity predict lymphocyte recovery and outcomes after matched-sibling hematopoietic stem cell transplant. Haematologica. 2013;98(3):346-352.

11. Toubert A, Glauzy S, Douay C, Clave E. Thymus and immune reconstitution after allogeneic hematopoietic stem cell transplantation in humans: never say never again. Tissue Antigens. 2012;79(2):83-89.

12. Maris $\mathrm{M}$, Boeckh $\mathrm{M}$, Storer B, et al. Immunologic recovery after hematopoietic cell transplantation with nonmyeloablative conditioning. Exp Hematol. 2003;31(10):941-952.

13. Petersen SL, Ryder LP, Bjork P, et al. A comparison of T-, B- and NK-cell reconstitution following conventional or nonmyeloablative conditioning and transplantation with bone marrow or peripheral blood stem cells from human leucocyte antigen identical sibling donors. Bone Marrow Transplant. 2003;32(1):65-72.

14. Schulenburg A, Fischer M, Kalhs P, et al. Immune recovery after conventional and nonmyeloablative allogeneic stem cell transplantation. Leuk Lymphoma. 2005;46(12):17551760.

15. Jimenez M, Martinez C, Ercilla G, et al. Reduced-intensity conditioning regimen preserves thymic function in the early period after hematopoietic stem cell transplantation. Exp Hematol. 2005;33(10):1240-1248.

16. Busca A, Lovisone E, Aliberti S, et al. Immune reconstitution and early infectious complications following nonmyeloablative hematopoietic stem cell transplantation. Hematology. 2003;8(5):303-311. 
17. Jacobson CA, Sun L, Kim HT, et al. Post-Transplantation B Cell Activating Factor and B Cell Recovery before Onset of Chronic Graft-versus-Host Disease. Biol Blood Marrow Transplant. 2014;20(5):668-675.

18. Na IK, Lu SX, Yim NL, et al. The cytolytic molecules Fas ligand and TRAIL are required for murine thymic graft-versus-host disease. J Clin Invest. 2010;120(1):343-356.

19. Mensen A, Johrens K, Anagnostopoulos I, et al. Bone marrow T-cell infiltration during acute GVHD is associated with delayed B-cell recovery and function after HSCT. Blood. 2014;124(6):963-972.

20. Glauzy S, Soret J, Fournier I, et al. Impact of acute and chronic graft-versus-host disease on human B-cell generation and replication. Blood. 2014;124(15):2459-2462.

21. Perez-Andres M, Paiva B, Nieto WG, et al. Human peripheral blood B-cell compartments: a crossroad in B-cell traffic. Cytometry B Clin Cytom. 2010;78 Suppl 1:S47-60.

22. LeBien TW, Tedder TF. B lymphocytes: how they develop and function. Blood. 2008;112(5):1570-1580.

23. Wardemann H, Yurasov S, Schaefer A, Young JW, Meffre E, Nussenzweig MC. Predominant autoantibody production by early human B cell precursors. Science. 2003;301(5638):1374-1377.

24. Miklos DB, Kim HT, Miller $\mathrm{KH}$, et al. Antibody responses to $\mathrm{H}-\mathrm{Y}$ minor histocompatibility antigens correlate with chronic graft-versus-host disease and disease remission. Blood. 2005;105(7):2973-2978.

25. Miklos DB, Kim HT, Zorn E, et al. Antibody response to DBY minor histocompatibility antigen is induced after allogeneic stem cell transplantation and in healthy female donors. Blood. 2004;103(1):353-359. 
26. Bellucci R, Alyea EP, Chiaretti S, et al. Graft-versus-tumor response in patients with multiple myeloma is associated with antibody response to BCMA, a plasma-cell membrane receptor. Blood. 2005;105(10):3945-3950.

27. Bellucci R, Wu CJ, Chiaretti S, et al. Complete response to donor lymphocyte infusion in multiple myeloma is associated with antibody responses to highly expressed antigens. Blood. 2004;103(2):656-663.

28. Filipovich AH, Weisdorf D, Pavletic S, et al. National Institutes of Health consensus development project on criteria for clinical trials in chronic graft-versus-host disease: I. Diagnosis and staging working group report. Biol Blood Marrow Transplant. 2005;11(12):945-956.

29. Blazar BR, Murphy WJ, Abedi M. Advances in graft-versus-host disease biology and therapy. Nat Rev Immunol. 2012;12(6):443-458.

30. Socie G, Ritz J. Current issues in chronic graft-versus-host disease. Blood. 2014;124(3):374-384.

31. Lee SJ. New approaches for preventing and treating chronic graft-versus-host disease. Blood. 2005;105(11):4200-4206.

32. Cutler C, Miklos D, Kim HT, et al. Rituximab for steroid-refractory chronic graft-versushost disease. Blood. 2006;108(2):756-762.

33. Flowers ME, Parker PM, Johnston LJ, et al. Comparison of chronic graft-versus-host disease after transplantation of peripheral blood stem cells versus bone marrow in allogeneic recipients: long-term follow-up of a randomized trial. Blood. 2002;100(2):415419. 
34. Zhang H, Chen J, Que W. A meta-analysis of unrelated donor umbilical cord blood transplantation versus unrelated donor bone marrow transplantation in acute leukemia patients. Biol Blood Marrow Transplant. 2012;18(8):1164-1173.

35. Rocha V, Wagner JE, Jr., Sobocinski KA, et al. Graft-versus-host disease in children who have received a cord-blood or bone marrow transplant from an HLA-identical sibling. Eurocord and International Bone Marrow Transplant Registry Working Committee on Alternative Donor and Stem Cell Sources. N Engl J Med. 2000;342(25):1846-1854.

36. Schrezenmeier H, Passweg JR, Marsh JC, et al. Worse outcome and more chronic GVHD with peripheral blood progenitor cells than bone marrow in HLA-matched sibling donor transplants for young patients with severe acquired aplastic anemia. Blood. 2007;110(4):1397-1400.

37. Pavletic SZ, Carter SL, Kernan NA, et al. Influence of T-cell depletion on chronic graftversus-host disease: results of a multicenter randomized trial in unrelated marrow donor transplantation. Blood. 2005;106(9):3308-3313.

38. Lee SJ, Vogelsang G, Flowers ME. Chronic graft-versus-host disease. Biol Blood Marrow Transplant. 2003;9(4):215-233.

39. Remberger M, Kumlien G, Aschan J, et al. Risk factors for moderate-to-severe chronic graft-versus-host disease after allogeneic hematopoietic stem cell transplantation. Biol Blood Marrow Transplant. 2002;8(12):674-682.

40. Randolph SS, Gooley TA, Warren EH, Appelbaum FR, Riddell SR. Female donors contribute to a selective graft-versus-leukemia effect in male recipients of HLA-matched, related hematopoietic stem cell transplants. Blood. 2004;103(1):347-352. 
41. Bates JS, Engemann AM, Hammond JM. Clinical utility of rituximab in chronic graftversus-host disease. Ann Pharmacother. 2009;43(2):316-321.

42. Quinn JP, Mohamedbhai S, Chipperfield K, Treacy M, D'Sa S, Nathwani AC. Efficacy of rituximab in combination with steroids in refractory chronic lymphocytic leukemia. Leuk Lymphoma. 2008;49(10):1995-1998.

43. von Bonin M, Oelschlagel U, Radke J, et al. Treatment of chronic steroid-refractory graftversus-host disease with low-dose rituximab. Transplantation. 2008;86(6):875-879.

44. Sarantopoulos S, Stevenson KE, Kim HT, et al. Altered B-cell homeostasis and excess BAFF in human chronic graft-versus-host disease. Blood. 2009;113(16):3865-3874.

45. Sarantopoulos S, Stevenson KE, Kim HT, et al. High levels of B-cell activating factor in patients with active chronic graft-versus-host disease. Clin Cancer Res. 2007;13(20):61076114.

46. Allen JL, Fore MS, Wooten J, et al. B cells from patients with chronic GVHD are activated and primed for survival via BAFF-mediated pathways. Blood. 2012;120(12):2529-2536.

47. Jacobson CA, Ritz J. B-cell-directed therapy for chronic graft-versus-host disease. Haematologica. 2010;95(11):1811-1813.

48. Kaminski DA, Wei C, Qian Y, Rosenberg AF, Sanz I. Advances in human B cell phenotypic profiling. Front Immunol. 2012;3:302.

49. Khoder A, Sarvaria A, Alsuliman A, et al. Regulatory B cells are enriched within the IgM memory and transitional subsets in healthy donors but are deficient in chronic GVHD. Blood. 2014;124(13):2034-2045.

50. de Masson A, Bouaziz JD, Le Buanec H, et al. CD24hiCD27+ and plasmablast-like regulatory B cells in human chronic graft-versus-host disease. Blood. 2015. 
51. Seggewiss R, Einsele H. Immune reconstitution after allogeneic transplantation and expanding options for immunomodulation: an update. Blood. 2010;115(19):3861-3868.

52. Tomblyn M, Chiller T, Einsele H, et al. Guidelines for preventing infectious complications among hematopoietic cell transplantation recipients: a global perspective. Biol Blood Marrow Transplant. 2009;15(10):1143-1238.

53. Robin M, Porcher R, De Castro Araujo R, et al. Risk factors for late infections after allogeneic hematopoietic stem cell transplantation from a matched related donor. Biol Blood Marrow Transplant. 2007;13(11):1304-1312.

54. Corre E, Carmagnat M, Busson M, et al. Long-term immune deficiency after allogeneic stem cell transplantation: B-cell deficiency is associated with late infections. Haematologica. 2010;95(6):1025-1029.

55. Kuijpers TW, Bende RJ, Baars PA, et al. CD20 deficiency in humans results in impaired T cell-independent antibody responses. J Clin Invest. 2010;120(1):214-222.

56. Jacobson CA, Turki AT, McDonough SM, et al. Immune reconstitution after double umbilical cord blood stem cell transplantation: comparison with unrelated peripheral blood stem cell transplantation. Biol Blood Marrow Transplant. 2012;18(4):565-574.

57. Jacquot S. CD27/CD70 interactions regulate T dependent B cell differentiation. Immunol Res. 2000;21(1):23-30.

58. Bohnhorst JO, Bjorgan MB, Thoen JE, Natvig JB, Thompson KM. Bm1-Bm5 classification of peripheral blood B cells reveals circulating germinal center founder cells in healthy individuals and disturbance in the B cell subpopulations in patients with primary Sjogren's syndrome. J Immunol. 2001;167(7):3610-3618. 
59. Chen K, Cerutti A. New insights into the enigma of immunoglobulin D. Immunol Rev. 2010;237(1):160-179.

60. Orciani M, Trubiani O, Guarnieri S, Ferrero E, Di Primio R. CD38 is constitutively expressed in the nucleus of human hematopoietic cells. $J$ Cell Biochem. 2008;105(3):905912.

61. Malavasi F, Deaglio S, Funaro A, et al. Evolution and function of the ADP ribosyl cyclase/CD38 gene family in physiology and pathology. Physiol Rev. 2008;88(3):841-886.

62. Anolik JH, Barnard J, Cappione A, et al. Rituximab improves peripheral B cell abnormalities in human systemic lupus erythematosus. Arthritis Rheum. 2004;50(11):3580-3590.

63. Eibel H, Kraus H, Sic H, Kienzler AK, Rizzi M. B cell biology: an overview. Curr Allergy Asthma Rep. 2014;14(5):434.

64. Meffre E, Casellas R, Nussenzweig MC. Antibody regulation of B cell development. Nat Immunol. 2000;1(5):379-385.

65. Palanichamy A, Barnard J, Zheng B, et al. Novel human transitional B cell populations revealed by B cell depletion therapy. J Immunol. 2009;182(10):5982-5993.

66. Gowthaman U, Chodisetti SB, Agrewala JN. T cell help to B cells in germinal centers: putting the jigsaw together. Int Rev Immunol. 2010;29(4):403-420.

67. Gatto D, Brink R. The germinal center reaction. J Allergy Clin Immunol. 2010;126(5):898907; quiz 908-899.

68. Wehrli N, Legler DF, Finke D, et al. Changing responsiveness to chemokines allows medullary plasmablasts to leave lymph nodes. Eur J Immunol. 2001;31(2):609-616. 
69. Payne D, Drinkwater S, Baretto R, Duddridge M, Browning MJ. Expression of chemokine receptors $\mathrm{CXCR} 4, \mathrm{CXCR} 5$ and $\mathrm{CCR} 7$ on $\mathrm{B}$ and $\mathrm{T}$ lymphocytes from patients with primary antibody deficiency. Clin Exp Immunol. 2009;156(2):254-262.

70. Shi Y, Agematsu K, Ochs HD, Sugane K. Functional analysis of human memory B-cell subpopulations: $\operatorname{IgD}+\mathrm{CD} 27+\mathrm{B}$ cells are crucial in secondary immune response by producing high affinity IgM. Clin Immunol. 2003;108(2):128-137.

71. Tangye SG, Good KL. Human IgM+CD27+ B cells: memory B cells or "memory" B cells? J Immunol. 2007;179(1):13-19.

72. Tarlinton D, Good-Jacobson K. Diversity among memory B cells: origin, consequences, and utility. Science. 2013;341(6151):1205-1211.

73. Tarlinton D. B-cell memory: are subsets necessary? Nat Rev Immunol. 2006;6(10):785790.

74. Chaudhuri J, Alt FW. Class-switch recombination: interplay of transcription, DNA deamination and DNA repair. Nat Rev Immunol. 2004;4(7):541-552.

75. Nicholson JK, Hubbard M, Jones BM. Use of CD45 fluorescence and side-scatter characteristics for gating lymphocytes when using the whole blood lysis procedure and flow cytometry. Cytometry. 1996;26(1):16-21.

76. Storek J, Lalovic BB, Rupert K, Dawson MA, Shen DD, Maloney DG. Kinetics of B, CD4 $\mathrm{T}$, and CD8 T cells infused into humans: estimates of intravascular:extravascular ratios and total body counts. Clin Immunol. 2002;102(3):249-257.

77. Marie-Cardine A, Divay F, Dutot I, et al. Transitional B cells in humans: characterization and insight from B lymphocyte reconstitution after hematopoietic stem cell transplantation. Clin Immunol. 2008;127(1):14-25. 
78. Meyer-Bahlburg A, Andrews SF, Yu KO, Porcelli SA, Rawlings DJ. Characterization of a late transitional B cell population highly sensitive to BAFF-mediated homeostatic proliferation. J Exp Med. 2008;205(1):155-168.

79. Cancro MP. Peripheral B-cell maturation: the intersection of selection and homeostasis. Immunol Rev. 2004;197:89-101.

80. Coutinho A, Moller G. Thymus-independent B-cell induction and paralysis. Adv Immunol. 1975;21:113-236.

81. Kuzmina Z, Greinix HT, Weigl R, et al. Significant differences in B-cell subpopulations characterize patients with chronic graft-versus-host disease-associated dysgammaglobulinemia. Blood. 2011;117(7):2265-2274.

82. Greinix HT, Pohlreich D, Kouba M, et al. Elevated numbers of immature/transitional CD21- B lymphocytes and deficiency of memory CD27+ B cells identify patients with active chronic graft-versus-host disease. Biol Blood Marrow Transplant. 2008;14(2):208219.

83. Sims GP, Ettinger R, Shirota Y, Yarboro CH, Illei GG, Lipsky PE. Identification and characterization of circulating human transitional B cells. Blood. 2005;105(11):4390-4398.

84. Wehr C, Eibel H, Masilamani M, et al. A new CD21 low B cell population in the peripheral blood of patients with SLE. Clin Immunol. 2004;113(2):161-171.

85. Cyster JG, Hartley SB, Goodnow CC. Competition for follicular niches excludes selfreactive cells from the recirculating B-cell repertoire. Nature. 1994;371(6496):389-395.

86. Lesley R, Xu Y, Kalled SL, et al. Reduced competitiveness of autoantigen-engaged B cells due to increased dependence on BAFF. Immunity. 2004;20(4):441-453. 
87. Defrance T, Taillardet M, Genestier L. T cell-independent B cell memory. Curr Opin Immunol. 2011;23(3):330-336.

88. Rodriguez-Bayona B, Ramos-Amaya A, Perez-Venegas JJ, Rodriguez C, Brieva JA. Decreased frequency and activated phenotype of blood CD27 IgD IgM B lymphocytes is a permanent abnormality in systemic lupus erythematosus patients. Arthritis Res Ther. 2010;12(3):R108.

89. Roberts ME, Kaminski D, Jenks SA, et al. Primary Sjogren's syndrome is characterized by distinct phenotypic and transcriptional profiles of $\operatorname{IgD}+$ unswitched memory B cells. Arthritis Rheumatol. 2014;66(9):2558-2569.

90. Arce E, Jackson DG, Gill MA, Bennett LB, Banchereau J, Pascual V. Increased frequency of pre-germinal center B cells and plasma cell precursors in the blood of children with systemic lupus erythematosus. J Immunol. 2001;167(4):2361-2369.

91. Storek J, Geddes M, Khan F, et al. Reconstitution of the immune system after hematopoietic stem cell transplantation in humans. Semin Immunopathol. 2008;30(4):425437.

92. Crotty S. A brief history of T cell help to B cells. Nat Rev Immunol. 2015.

93. Flynn R, Du J, Veenstra RG, et al. Increased T follicular helper cells and germinal center B cells are required for cGVHD and bronchiolitis obliterans. Blood. 2014;123(25):39883998.

94. Kerfoot SM, Yaari G, Patel JR, et al. Germinal center B cell and T follicular helper cell development initiates in the interfollicular zone. Immunity. 2011;34(6):947-960.

95. Daien CI, Gailhac S, Mura T, Combe B, Hahne M, Morel J. High levels of memory B cells are associated with response to a first tumor necrosis factor inhibitor in patients with 
rheumatoid arthritis in a longitudinal prospective study. Arthritis Res Ther. 2014;16(2):R95.

96. Hilgendorf I, Mueller-Hilke B, Kundt G, et al. The lack of memory B cells including T cell independent IgM + IgD + memory B cells in chronic graft-versus host disease is associated with susceptibility to infection. Transpl Int. 2012;25(1):87-96.

97. Jacob J, Kelsoe G, Rajewsky K, Weiss U. Intraclonal generation of antibody mutants in germinal centres. Nature. 1991;354(6352):389-392.

98. Avery DT, Kalled SL, Ellyard JI, et al. BAFF selectively enhances the survival of plasmablasts generated from human memory B cells. J Clin Invest. 2003;112(2):286-297.

99. Odendahl M, Keitzer R, Wahn U, et al. Perturbations of peripheral B lymphocyte homoeostasis in children with systemic lupus erythematosus. Ann Rheum Dis. 2003;62(9):851-858.

100. Sarantopoulos S, Ritz J. Aberrant B cell homeostasis in chronic GVHD. Blood. 2015.

101. Young JS, Wu T, Chen Y, et al. Donor B cells in transplants augment clonal expansion and survival of pathogenic CD4+ T cells that mediate autoimmune-like chronic graft-versushost disease. J Immunol. 2012;189(1):222-233.

102. Kita H, Lian ZX, Van de Water J, et al. Identification of HLA-A2-restricted CD8(+) cytotoxic $\mathrm{T}$ cell responses in primary biliary cirrhosis: $\mathrm{T}$ cell activation is augmented by immune complexes cross-presented by dendritic cells. J Exp Med. 2002;195(1):113-123.

103. Rafiq K, Bergtold A, Clynes R. Immune complex-mediated antigen presentation induces tumor immunity. J Clin Invest. 2002;110(1):71-79.

104. Sarantopoulos S, Blazar BR, Cutler C, Ritz J. B Cells in Chronic Graft-versus-Host Disease. Biol Blood Marrow Transplant. 2015;21(1):16-23. 
105. Isnardi I, Ng YS, Menard L, et al. Complement receptor 2/CD21- human naive B cells contain mostly autoreactive unresponsive clones. Blood. 2010;115(24):5026-5036.

106. Warnatz K, Wehr C, Drager R, et al. Expansion of CD19(hi)CD21(lo/neg) B cells in common variable immunodeficiency (CVID) patients with autoimmune cytopenia. Immunobiology. 2002;206(5):502-513.

107. Turner M, Gulbranson-Judge A, Quinn ME, Walters AE, MacLennan IC, Tybulewicz VL. Syk tyrosine kinase is required for the positive selection of immature B cells into the recirculating B cell pool. J Exp Med. 1997;186(12):2013-2021.

108. Treml LS, Crowley JE, Cancro MP. BLyS receptor signatures resolve homeostatically independent compartments among naive and antigen-experienced B cells. Semin Immunol. 2006;18(5):297-304.

109. Sarantopoulos S, Stevenson KE, Kim HT, et al. Recovery of B-cell homeostasis after rituximab in chronic graft-versus-host disease. Blood. 2011;117(7):2275-2283.

110. de la Torre I, Moura RA, Leandro MJ, Edwards J, Cambridge G. B-cell-activating factor receptor expression on naive and memory B cells: relationship with relapse in patients with rheumatoid arthritis following B-cell depletion therapy. Ann Rheum Dis. 2010;69(12):2181-2188.

111. Sellam J, Miceli-Richard C, Gottenberg JE, et al. Decreased B cell activating factor receptor expression on peripheral lymphocytes associated with increased disease activity in primary Sjogren's syndrome and systemic lupus erythematosus. Ann Rheum Dis. 2007;66(6):790-797. 
Appendix 


\begin{tabular}{|l|l|}
\hline Antigen naive & Subset \\
\hline CD19+ CD27- IgD + CD38 low/- & Naïve B cells \\
\hline CD19+ CD27- IgD+ CD38+ & Transitional B cells \\
\hline Antigen experienced & \\
\hline CD19+ CD27+ IgD+ CD38 low/- & IgD Memory B cells \\
\hline CD19+ CD27+ IgD+ CD38+ & Pre-germinal Center B cells \\
\hline CD19+ CD27+ IgD low/- CD38 low/- & Post-germinal Center Memory \\
\hline CD19+ CD27+ IgD low/- CD38+ & Plasmablast/Plasma cell \\
\hline
\end{tabular}

Table 1: B cell subsets identified in peripheral blood 


\begin{tabular}{|c|c|c|c|c|c|c|c|c|}
\hline Day & -6 & -5 & -4 & -3 & -2 & -1 & 0 & +12 \\
\hline Cyclophosphamide & + & + & & & & & & \\
\hline TBI & & & + & + & + & + & & \\
\hline Stem cell infusion & & & & & & & + & \\
\hline Filgastrim & & & & & & & & + \\
\hline
\end{tabular}

Table 2: TP 764 myeloablative conditioning regimen

\begin{tabular}{|c|c|c|c|c|c|c|c|}
\hline Day & -5 & -4 & -3 & -2 & -1 & 0 & +1 \\
\hline Fludarabine & + & + & + & + & & & \\
\hline Busulfan & + & + & + & + & & & \\
\hline Stem cell infusion & & & & & & + & \\
\hline Filgastrim & & & & & & & + \\
\hline
\end{tabular}

Table 3: TP 855 reduced intensity conditioning regimen 


\begin{tabular}{|c|c|}
\hline $\begin{array}{c}\text { Fluorophore-conjugated } \\
\text { monoclonal antibodies }\end{array}$ & B cell surface marker \\
\hline FITC & BAFF-R \\
\hline PE & IgD \\
\hline PE-Cy5 & CD27 \\
\hline PE-Cy7 & CD38 \\
\hline APC & CD19 \\
\hline APC-H7 & CD20 \\
\hline PACIFIC BLUE & CD5 \\
\hline PACIFIC ORANGE & CD45 \\
\hline
\end{tabular}

Table 4: Fluorophore-conjugated monoclonal antibodies specific for B cell surface markers 


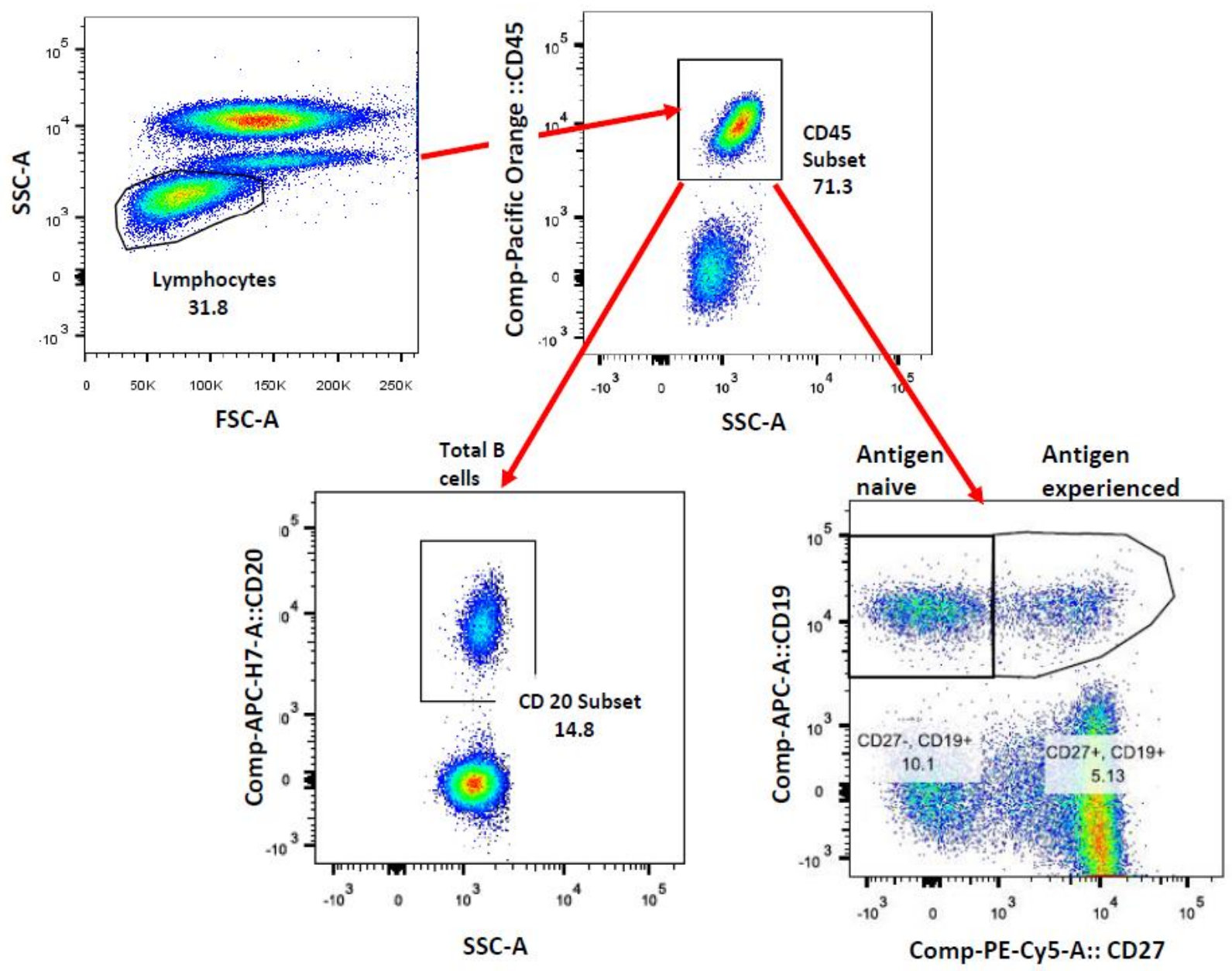

Figure 1: Gating of major subgroups, lymphocytes, CD45, CD20 and CD19+CD27+/- 

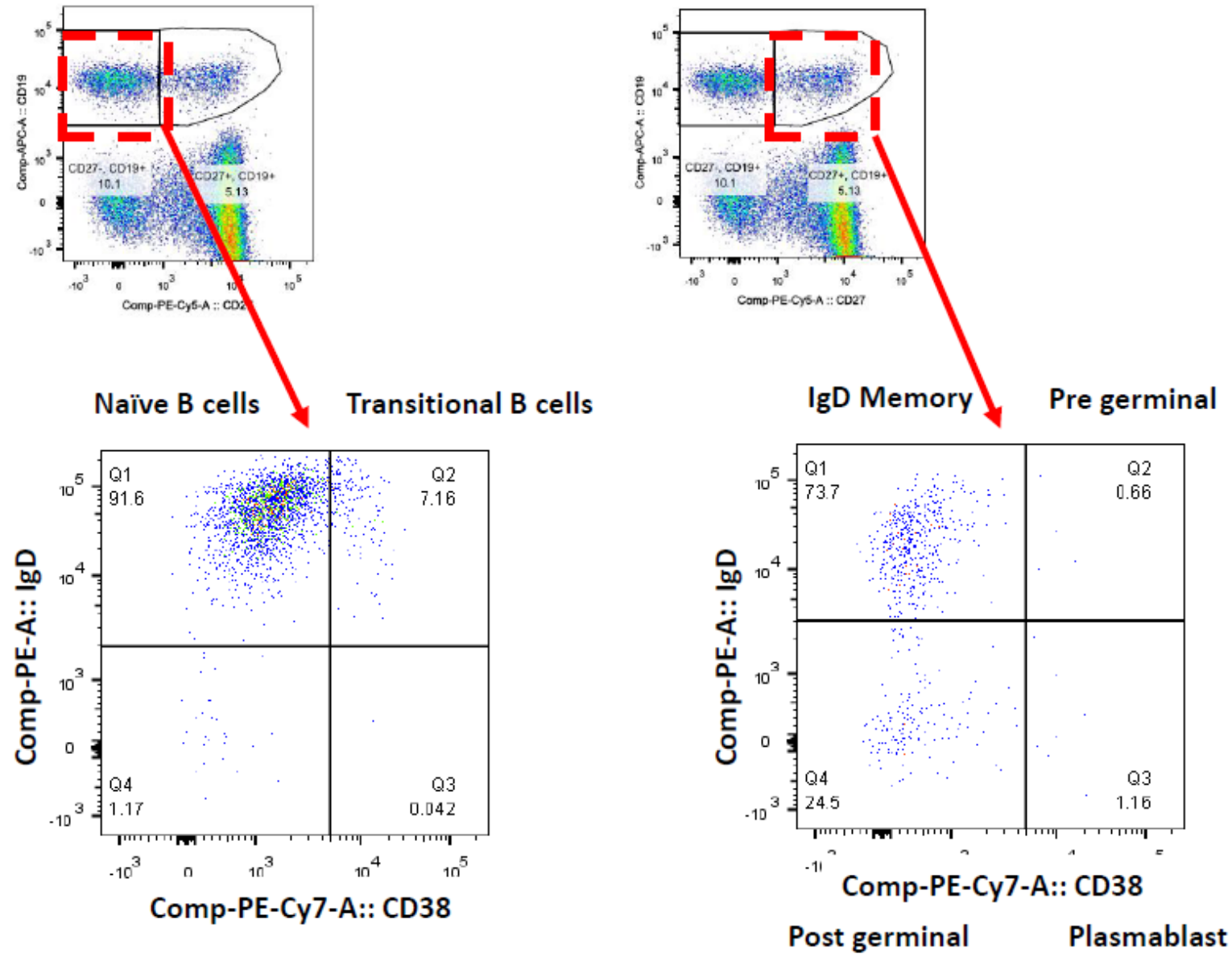

Figure 2: $\mathrm{B}$ cell subsets as gated $\mathrm{IgD}$ vs $\mathrm{CD} 38$ 


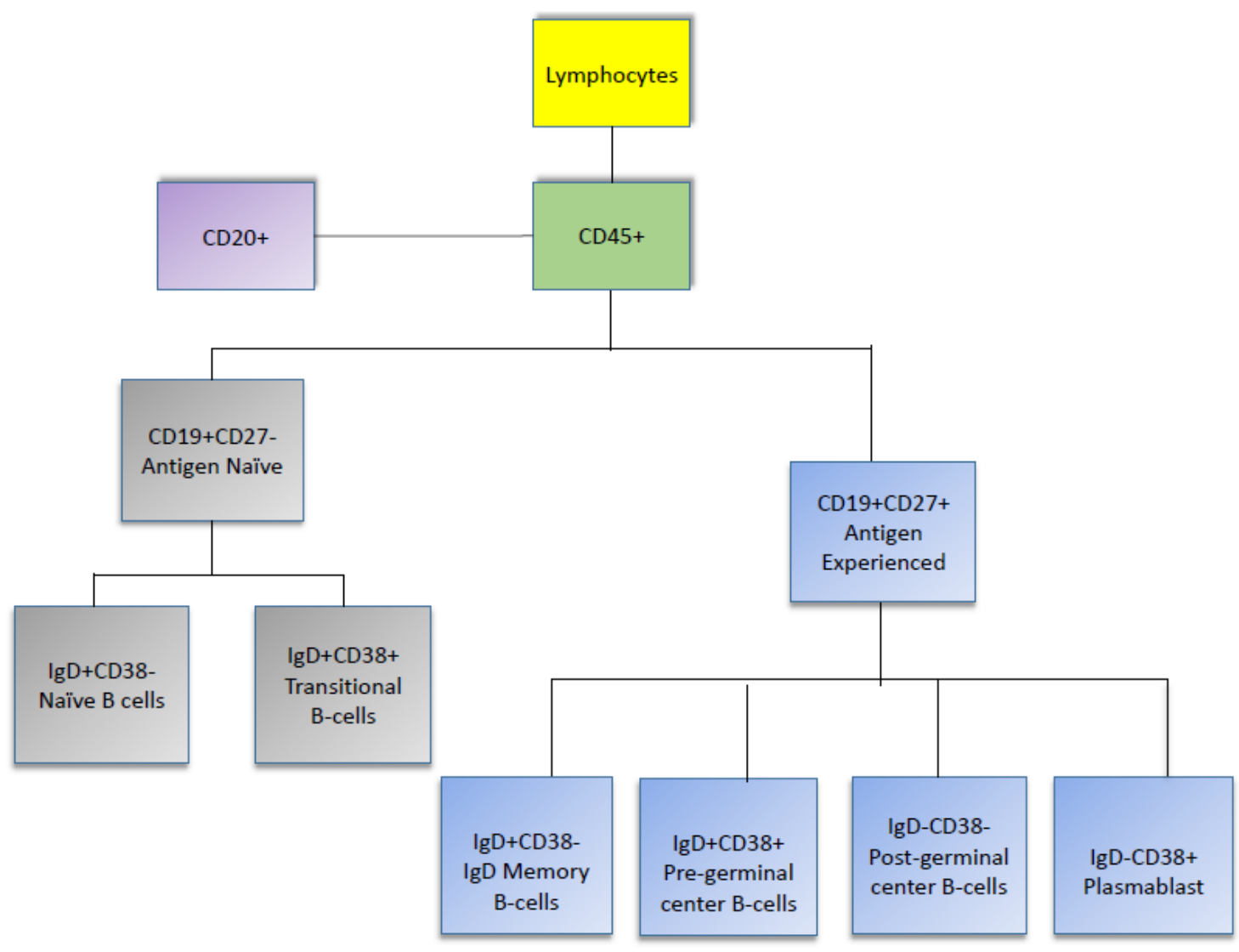

Figure 3: Subset populations 


\begin{tabular}{|c|c|c|c|c|c|c|}
\hline & \multicolumn{2}{|c|}{ MAC } & \multicolumn{2}{|c|}{ RIC } & \multicolumn{2}{|c|}{ All } \\
\hline & $\mathrm{N}$ & $\%$ & $\mathrm{~N}$ & $\%$ & $\mathrm{~N}$ & $\%$ \\
\hline Total & 91 & 22.8 & 308 & 77.2 & 399 & 100 \\
\hline Age, median (range) & \multicolumn{2}{|c|}{$44(21,60)$} & \multicolumn{2}{|c|}{$62(19,74)$} & \multicolumn{2}{|c|}{$58(19,74)$} \\
\hline Patient Sex & & & & & & \\
\hline Male & 47 & 51.6 & 177 & 57.5 & 224 & 56.1 \\
\hline Female & 44 & 48.4 & 131 & 42.5 & 175 & 43.9 \\
\hline \multicolumn{7}{|l|}{ Donor Sex } \\
\hline Male & 51 & 56 & 197 & 64 & 248 & 62.2 \\
\hline Female & 40 & 44 & 111 & 36 & 151 & 37.8 \\
\hline \multicolumn{7}{|l|}{ Patient-Donor Sex } \\
\hline $\mathrm{MM}$ & 31 & 34.1 & 119 & 38.6 & 150 & 37.6 \\
\hline MF & 16 & 17.6 & 58 & 18.8 & 74 & 18.5 \\
\hline FM & 20 & 22 & 78 & 25.3 & 98 & 24.6 \\
\hline $\mathrm{FF}$ & 24 & 26.4 & 53 & 17.2 & 77 & 19.3 \\
\hline \multicolumn{7}{|l|}{ Primary Diagnosis } \\
\hline AML & 37 & 40.7 & 103 & 33.4 & 140 & 35.1 \\
\hline CML & 9 & 9.9 & 6 & 1.9 & 15 & 3.8 \\
\hline MDS & 6 & 6.6 & 62 & 20.1 & 68 & 17 \\
\hline MPD & 1 & 1.1 & 13 & 4.2 & 14 & 3.5 \\
\hline Mixed MDS/MPD & 2 & 2.2 & 5 & 1.6 & 7 & 1.8 \\
\hline ALL & 26 & 28.6 & 22 & 7.1 & 48 & 12 \\
\hline CLL, SLL, PLL & & & 18 & 5.8 & 18 & 4.5 \\
\hline NHL & 10 & 11 & 45 & 14.6 & 55 & 13.8 \\
\hline Hodgkin Disease & & & 12 & 3.9 & 12 & 3 \\
\hline $\mathrm{MM} / \mathrm{PCD}$ & & & 13 & 4.2 & 13 & 3.3 \\
\hline Anemia/ Red Cell Disorder & & & 4 & 1.3 & 4 & 1 \\
\hline Immunodeficiency & & & 2 & 0.6 & 2 & 0.5 \\
\hline Other Acute Leukemia & & & 2 & 0.6 & 2 & 0.5 \\
\hline Other Disease & & & 1 & 0.3 & 1 & 0.3 \\
\hline \multicolumn{7}{|l|}{ HLA type } \\
\hline Matched unrelated & 48 & 52.7 & 197 & 64 & 245 & 61.4 \\
\hline Matched related & 40 & 44 & 82 & 26.6 & 122 & 30.6 \\
\hline Mismatch unrelated & 3 & 3.3 & 29 & 9.4 & 32 & 8 \\
\hline \multicolumn{7}{|l|}{ Cell Source } \\
\hline Bone marrow & 7 & 7.7 & 16 & 5.2 & 23 & 5.8 \\
\hline PBSC & 84 & 92.3 & 290 & 94.2 & 374 & 93.7 \\
\hline Bone marrow and PBSC & & & 2 & 0.6 & 2 & 0.5 \\
\hline \multicolumn{7}{|l|}{ GVHD prophylaxis } \\
\hline Tac/Sir/MTX & & & 233 & 75.6 & 233 & 58.4 \\
\hline $\mathrm{Tac} / \mathrm{Sir} \pm \mathrm{MMF}$ & 5 & 5.5 & 59 & 19.1 & 64 & 16 \\
\hline $\mathrm{Tac} / \mathrm{MTX} \pm \mathrm{MMF}$ & 86 & 94.5 & 16 & 5.2 & 102 & 25.6 \\
\hline
\end{tabular}




\begin{tabular}{|l|cc|cc|cc|} 
Patient and Donor CMV & & & & & & \\
seropositivity & 66 & 72.5 & 221 & 71.8 & 287 & 71.9 \\
Positive & 24 & 26.4 & 84 & 27.3 & 108 & 27.1 \\
Negative & 1 & 1.1 & 3 & 1 & 4 & 1 \\
UNK & & & &
\end{tabular}

Table 5: Baseline Characteristics 


\begin{tabular}{|c|c|c|c|c|c|c|}
\hline & Month & N & Median & Min & Max & p-value \\
\hline \multirow{4}{*}{$\begin{array}{c}\text { aCD20 } \\
\text { (Total B cells) }\end{array}$} & 1 & 19 & 204 & 58.4 & 333.7 & HCT vs HD \\
\cline { 2 - 7 } & 2 & 289 & 4.9 & 0 & 158 & $<.0001$ \\
\cline { 2 - 7 } & 3 & 272 & 11.2 & 0 & 414.9 & $<.0001$ \\
\cline { 2 - 7 } & 6 & 190 & 45.3 & 0 & 337.6 & $<.0001$ \\
\cline { 2 - 7 } & 12 & 177 & 118.8 & 0 & 2058 & 0.022 \\
\cline { 2 - 7 } & 18 & 134 & 234.2 & 1.2 & 1698 & 0.7588 \\
\cline { 2 - 7 } & 24 & 109 & 232.9 & 6.9 & 1953 & 0.6778 \\
\cline { 2 - 7 } & 30 & 78 & 296.8 & 3.2 & 2414 & 0.189 \\
\cline { 2 - 7 } & 36 & 55 & 349.2 & 6.1 & 1766 & 0.0521 \\
\hline
\end{tabular}

Table 6: Absolute numbers of total B cells months' 1-36 post HCT vs HD

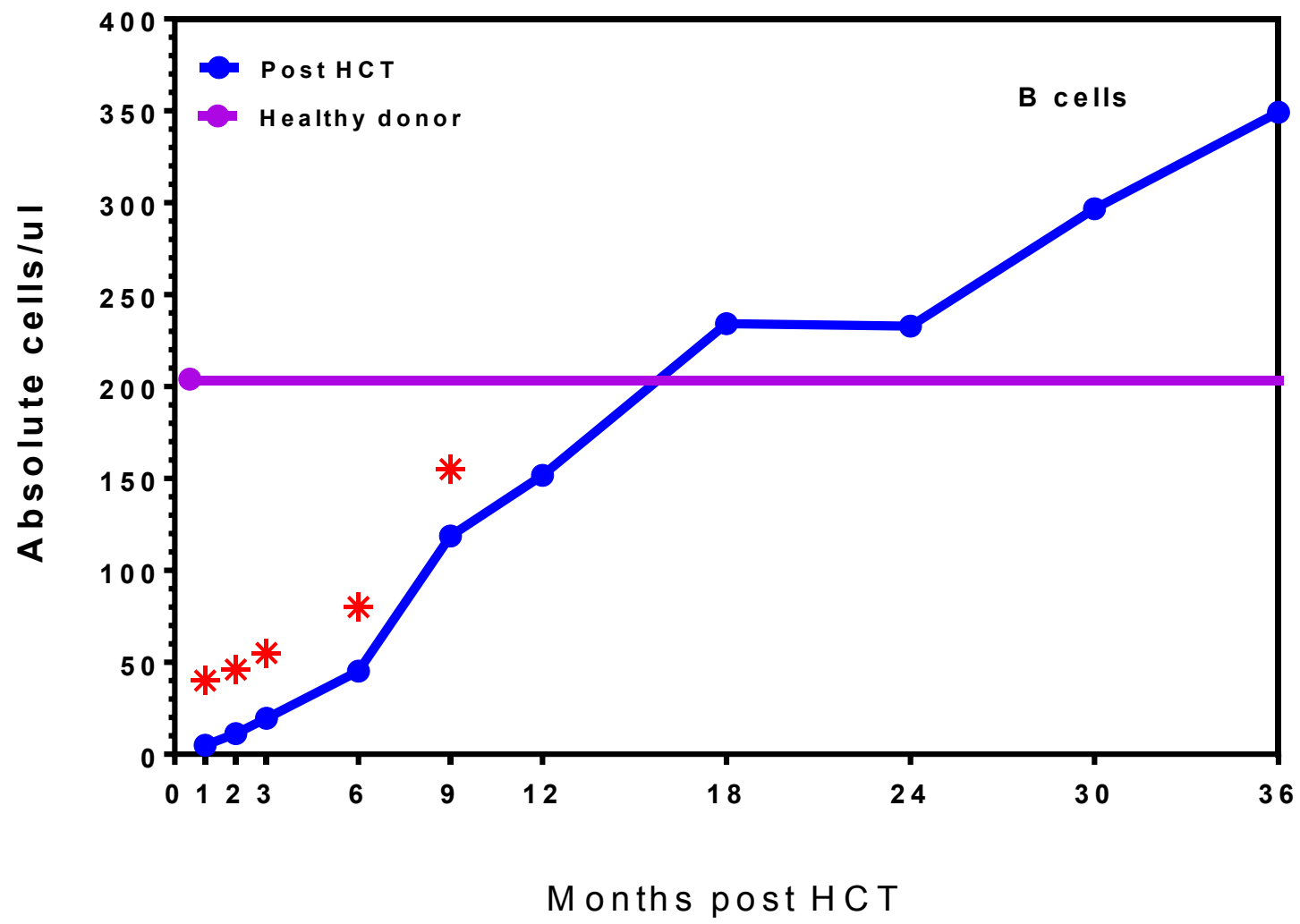

Figure 4: Recovery of total B cells vs HD (horizontal bar) * indicates significance 


\begin{tabular}{|c|c|c|c|c|c|c|}
\hline & Month & $\mathbf{N}$ & Median & Min & Max & p-value \\
\hline \multirow{11}{*}{$\begin{array}{c}\text { aCD19+27+ } \\
\text { (Antigen } \\
\text { Experienced) }\end{array}$} & $\mathrm{HD}$ & 19 & 55.2 & 18.1 & 96.2 & HCT vs HD \\
\hline & 1 & 289 & 1.1 & 0 & 58.5 & $<.0001$ \\
\hline & 2 & 272 & 1 & 0 & 150.9 & $<.0001$ \\
\hline & 3 & 276 & 1.4 & 0 & 333 & $<.0001$ \\
\hline & 6 & 190 & 1.9 & 0 & 84.4 & $<.0001$ \\
\hline & 9 & 177 & 3.8 & 0 & 116.8 & $<.0001$ \\
\hline & 12 & 167 & 5 & 0 & 449.8 & $<.0001$ \\
\hline & 18 & 134 & 8.2 & 0.1 & 97.1 & $<.0001$ \\
\hline & 24 & 109 & 9.8 & 0.1 & 524.5 & $<.0001$ \\
\hline & 30 & 78 & 12.4 & 0.1 & 142.2 & $<.0001$ \\
\hline & 36 & 55 & 15.9 & 0.1 & 106.1 & $<.0001$ \\
\hline
\end{tabular}

Table 7: Absolute numbers of antigen experienced months' 1-36 post HCT vs HD

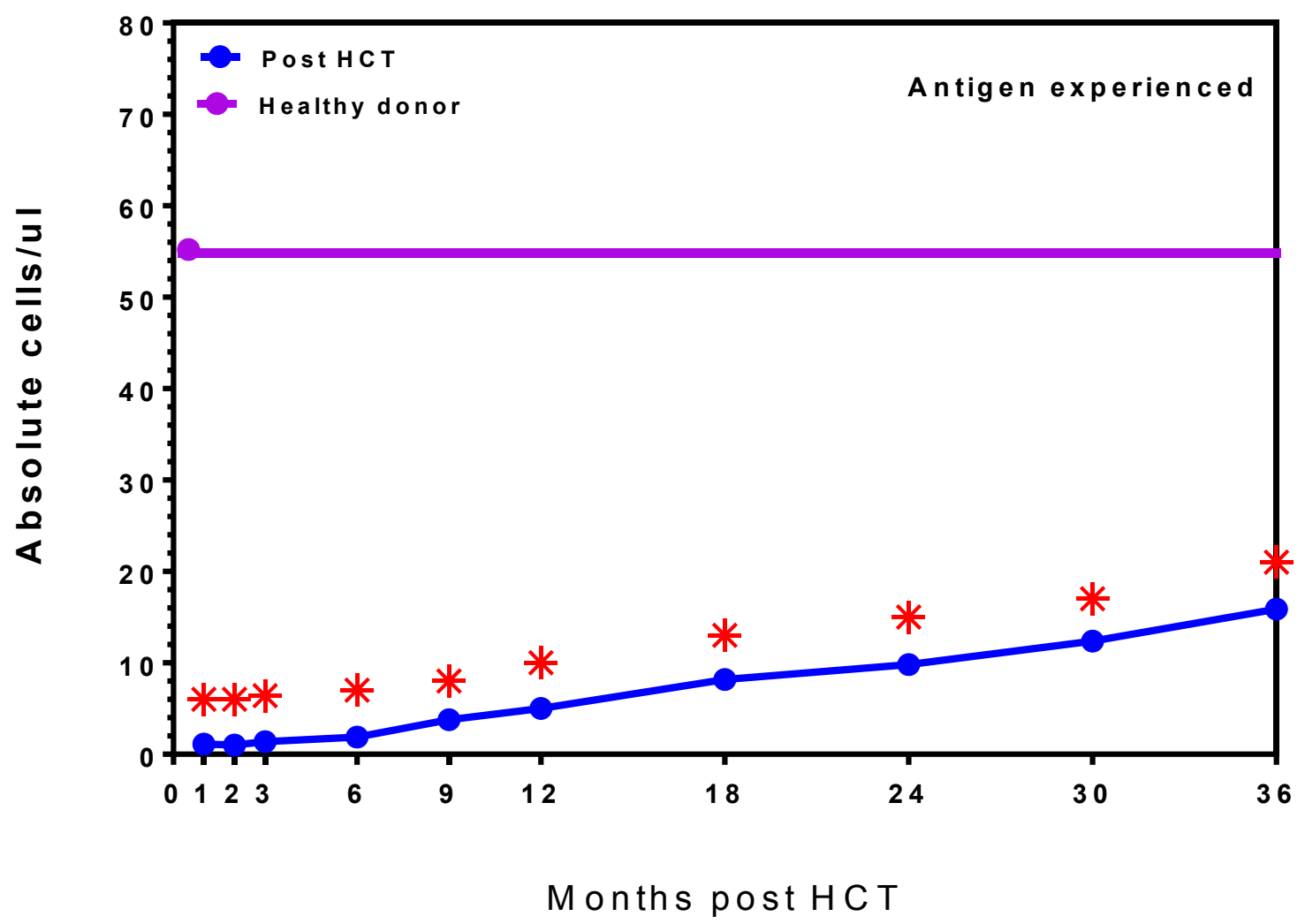

Figure 5: Absolute numbers of antigen experienced B cells vs HD (horizontal bar). * indicates significance 


\begin{tabular}{|c|c|c|c|c|c|c|}
\hline & Month & $\mathbf{N}$ & Median & Min & Max & p-value \\
\hline \multirow{11}{*}{$\begin{array}{c}\text { pCD19+27+ } \\
\text { (Antigen } \\
\text { Experienced) }\end{array}$} & HD & 19 & $3.30 \%$ & $1.10 \%$ & $6.60 \%$ & HCT vs HD \\
\hline & 1 & 289 & $0.20 \%$ & $0.00 \%$ & $4.80 \%$ & $<.0001$ \\
\hline & 2 & 272 & $0.20 \%$ & $0.00 \%$ & $10.20 \%$ & $<.0001$ \\
\hline & 3 & 276 & $0.20 \%$ & $0.00 \%$ & $12.00 \%$ & $<.0001$ \\
\hline & 6 & 190 & $0.30 \%$ & $0.00 \%$ & $6.40 \%$ & $<.0001$ \\
\hline & 9 & 177 & $0.40 \%$ & $0.00 \%$ & $7.00 \%$ & $<.0001$ \\
\hline & 12 & 167 & $0.40 \%$ & $0.00 \%$ & $24.50 \%$ & $<.0001$ \\
\hline & 18 & 134 & $0.50 \%$ & $0.00 \%$ & $5.00 \%$ & $<.0001$ \\
\hline & 24 & 109 & $0.60 \%$ & $0.00 \%$ & $18.60 \%$ & $<.0001$ \\
\hline & 30 & 78 & $0.80 \%$ & $0.00 \%$ & $6.10 \%$ & $<.0001$ \\
\hline & 36 & 55 & $0.80 \%$ & $0.00 \%$ & $7.60 \%$ & $<.0001$ \\
\hline
\end{tabular}

Table 8: Frequency of antigen experienced months' 1-36 post HCT vs HD

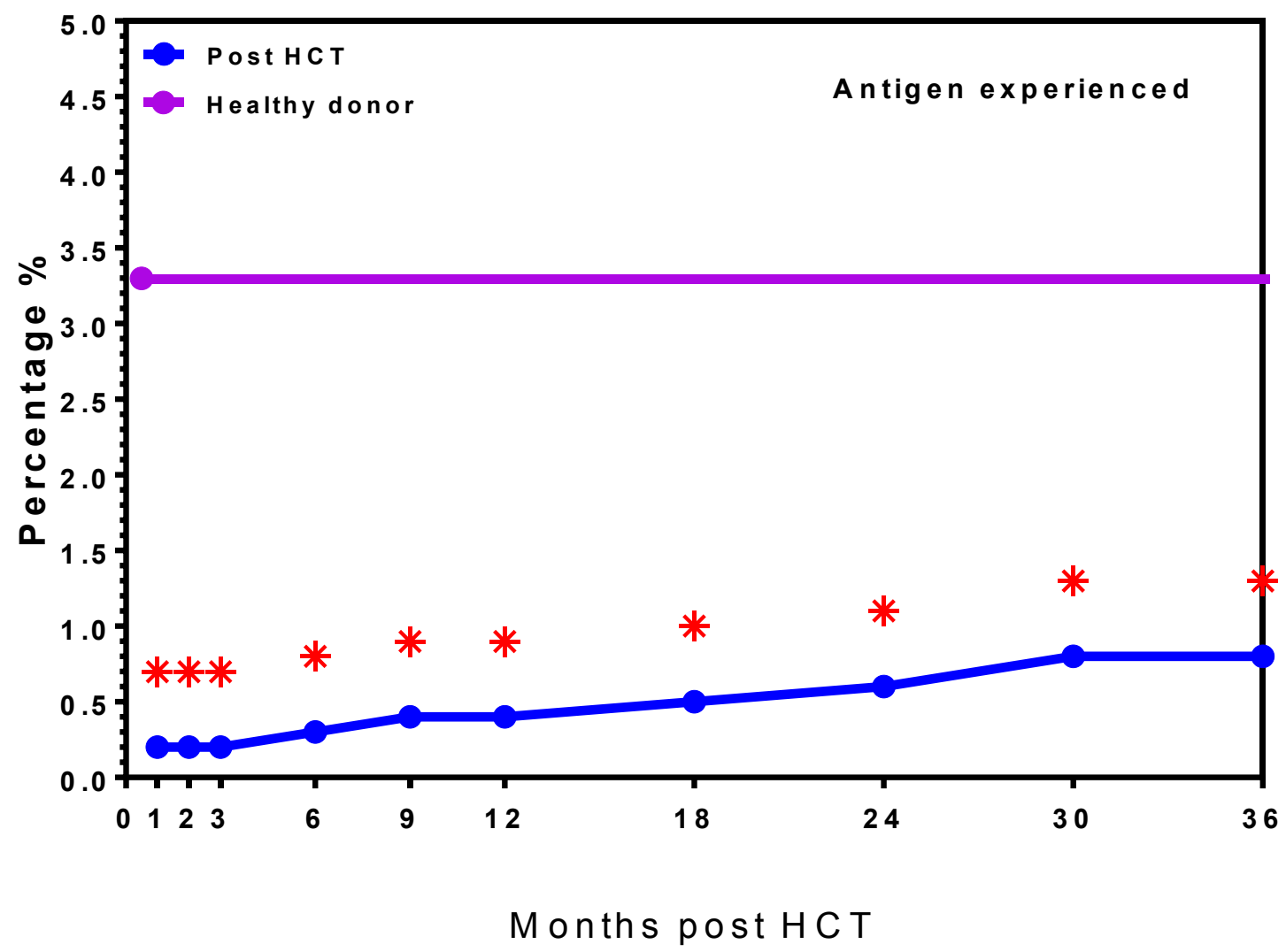

Figure 6: Frequency of antigen experienced B cells vs HD (horizontal bar) * indicates significance 


\begin{tabular}{|c|c|c|c|c|c|c|}
\hline & Month & $\mathbf{N}$ & Median & Min & Max & p-value \\
\hline \multirow{11}{*}{$\begin{array}{c}\text { aCD19+27- } \\
\text { (Antigen } \\
\text { Naive) }\end{array}$} & HD & 19 & 151 & 40.8 & 263.8 & $\begin{array}{c}\text { HCT vs } \\
\text { HD }\end{array}$ \\
\hline & 1 & 289 & 3.6 & 0 & 151.6 & $<.0001$ \\
\hline & 2 & 272 & 9.9 & 0 & 392 & $<.0001$ \\
\hline & 3 & 276 & 16.8 & 0 & 323.3 & $<.0001$ \\
\hline & 6 & 190 & 43.6 & 0 & 1286 & $<.0001$ \\
\hline & 9 & 177 & 108.7 & 0 & 2012 & 0.2384 \\
\hline & 12 & 167 & 132.3 & 0 & 1849 & 0.8537 \\
\hline & 18 & 134 & 208.9 & 0.6 & 1645 & 0.1641 \\
\hline & 24 & 109 & 229 & 4 & 1924 & 0.1845 \\
\hline & 30 & 78 & 277.9 & 2 & 2372 & 0.0534 \\
\hline & 36 & 55 & 321.7 & 5.1 & 1693 & 0.0143 \\
\hline
\end{tabular}

Table 9: Absolute numbers of antigen naïve months' 1-36 post HCT vs HD

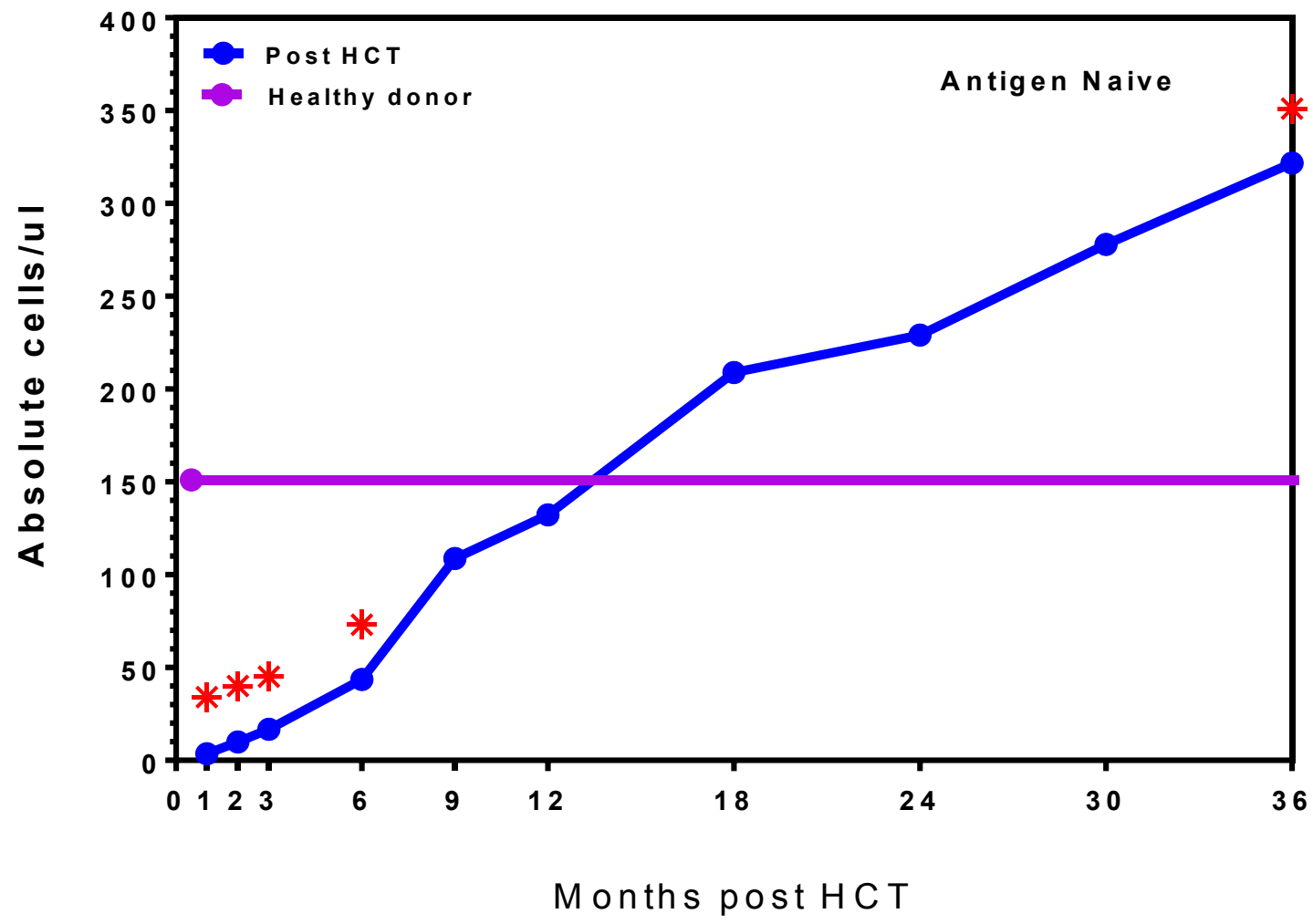

Figure 7: Absolute numbers of antigen naïve vs HD (horizontal bar) * indicates significance 


\begin{tabular}{|c|c|c|c|c|c|c|}
\hline & Month & N & Median & Min & Max & p-value \\
\hline & HD & 19 & $7.50 \%$ & $4.40 \%$ & $20.20 \%$ & $\begin{array}{c}\text { HCT vs } \\
\text { HD }\end{array}$ \\
\cline { 2 - 7 } & 1 & 289 & $6.40 \%$ & $0.00 \%$ & $70.00 \%$ & 0.4214 \\
\cline { 2 - 7 } & 2 & 272 & $29.40 \%$ & $0.00 \%$ & $90.10 \%$ & $<.0001$ \\
\cline { 2 - 7 } & 3 & 276 & $23.20 \%$ & $0.00 \%$ & $100.00 \%$ & $<.0001$ \\
\cline { 2 - 7 } & 6 & 190 & $21.00 \%$ & $0.00 \%$ & $84.20 \%$ & $<.0001$ \\
\cline { 2 - 7 } $\begin{array}{c}\text { IgD+CD38+ } \\
\text { (Transitional B } \\
\text { cells) }\end{array}$ & 9 & 177 & $12.50 \%$ & $0.00 \%$ & $84.70 \%$ & 0.0159 \\
\cline { 2 - 7 } & 12 & 167 & $10.90 \%$ & $0.00 \%$ & $69.60 \%$ & 0.1219 \\
\cline { 2 - 7 } & 24 & 134 & $9.00 \%$ & $0.00 \%$ & $43.10 \%$ & 0.4892 \\
\cline { 2 - 7 } & 30 & 78 & $8.40 \%$ & $0.10 \%$ & $36.00 \%$ & 0.6758 \\
\cline { 2 - 7 } & 36 & 55 & $7.50 \%$ & $0.00 \%$ & $22.10 \%$ & 0.9064 \\
\hline
\end{tabular}

Table 10: Frequency of transitional B cells months' 1-36 post HCT vs HD

\begin{tabular}{|c|c|c|c|c|c|c|}
\hline & Month & $\mathbf{N}$ & Median & Min & Max & p-value \\
\hline & HD & 19 & $87.20 \%$ & $75.10 \%$ & $92.40 \%$ & $\begin{array}{c}\text { HCT vs } \\
\text { HD }\end{array}$ \\
\cline { 2 - 7 } & 1 & 289 & $76.20 \%$ & $0.00 \%$ & $100.00 \%$ & 0.0001 \\
\cline { 2 - 7 } & 2 & 272 & $52.20 \%$ & $0.00 \%$ & $100.00 \%$ & $<.0001$ \\
\cline { 2 - 7 } & 3 & 276 & $68.10 \%$ & $0.00 \%$ & $100.00 \%$ & $<.0001$ \\
\cline { 2 - 7 } & 6 & 190 & $73.00 \%$ & $0.00 \%$ & $100.00 \%$ & $<.0001$ \\
\cline { 2 - 7 } pCD19+27- \\
IgD+CD38-
\end{tabular}

Table 11: Frequency of naive B cells months' 1-36 post HCT vs HD 


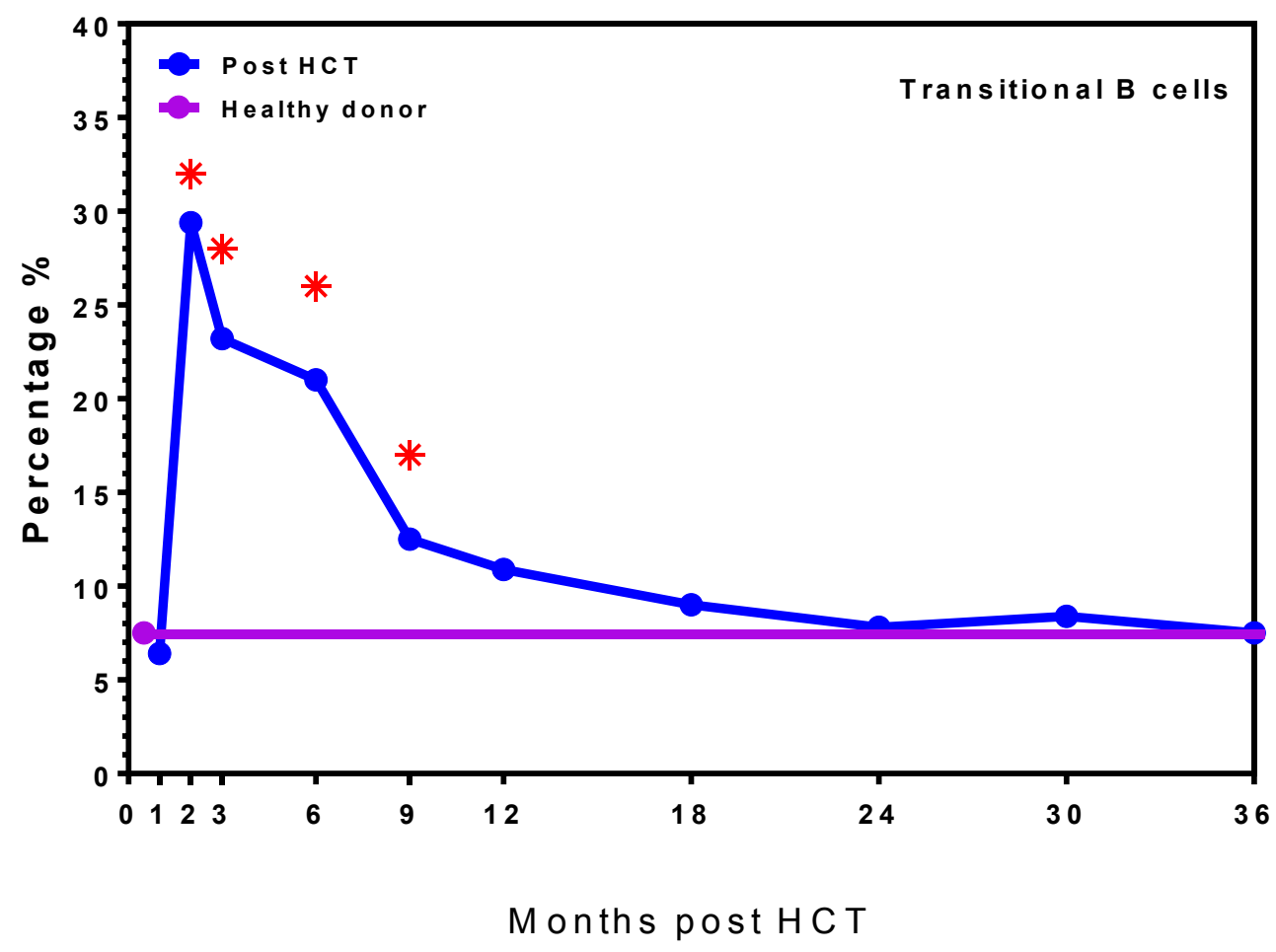

Figure 8: Frequency of transitional B cells vs HD (horizontal bar) * indicates significance

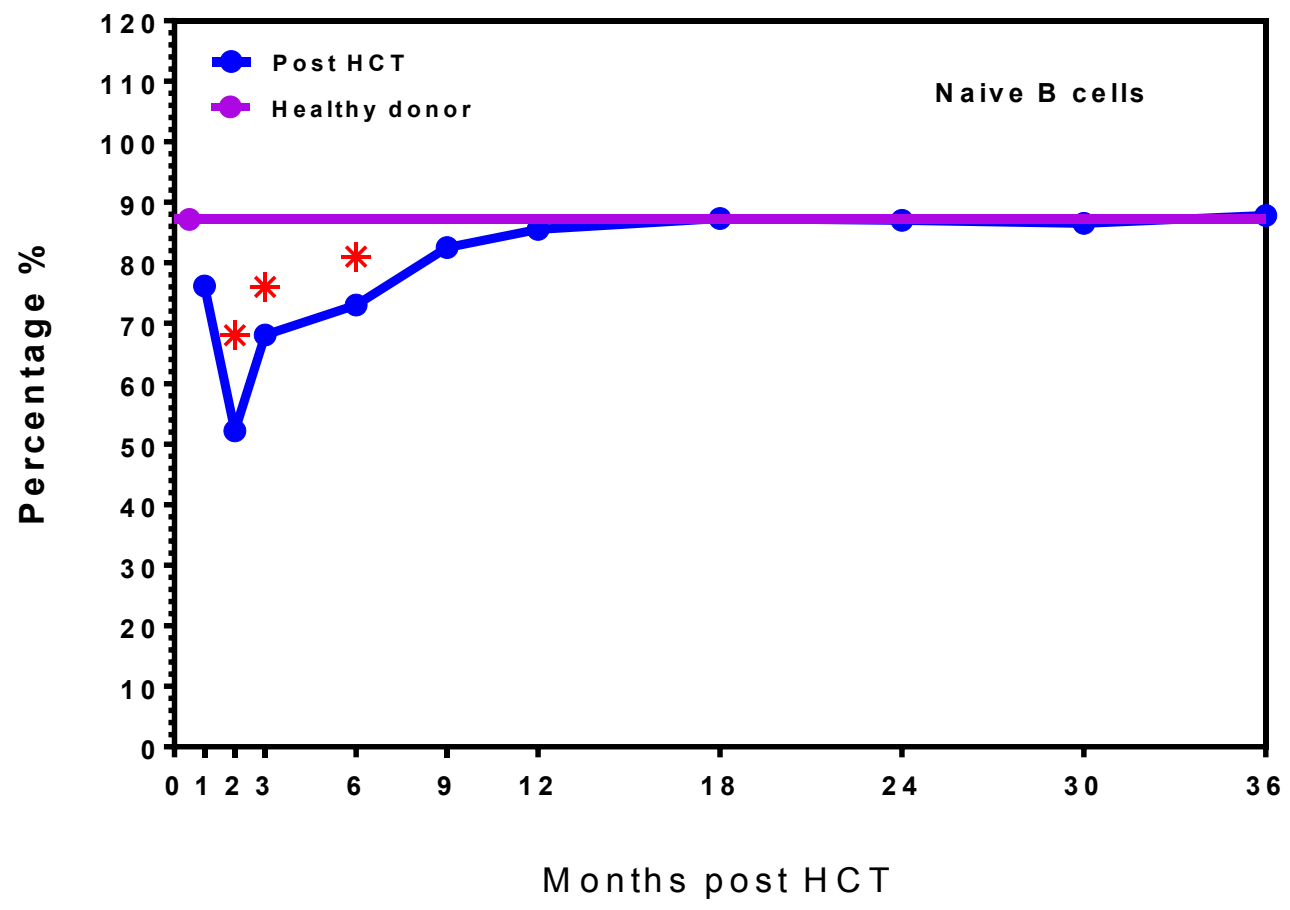

Figure 9: Frequency of naïve B cells vs HD (horizontal bar) * indicates significance 


\begin{tabular}{|c|c|c|c|c|c|c|}
\hline & Month & $\mathbf{N}$ & Median & Min & Max & p-value \\
\hline & HD & 19 & $42.00 \%$ & $16.20 \%$ & $75.80 \%$ & $\begin{array}{c}\text { HCT vs } \\
\text { HD }\end{array}$ \\
\cline { 2 - 7 } & 1 & 289 & $26.40 \%$ & $0.00 \%$ & $100.00 \%$ & 0.0031 \\
\cline { 2 - 7 } & 2 & 272 & $28.60 \%$ & $0.00 \%$ & $100.00 \%$ & 0.0078 \\
\cline { 2 - 7 } & 3 & 276 & $26.10 \%$ & $0.00 \%$ & $100.00 \%$ & 0.0085 \\
\cline { 2 - 7 } & 6 & 190 & $26.60 \%$ & $0.00 \%$ & $98.20 \%$ & 0.0095 \\
\cline { 2 - 7 } $\begin{array}{c}\text { pCD19+27+ } \\
\text { IgD+CD38- }\end{array}$ & 9 & 177 & $37.10 \%$ & $0.00 \%$ & $100.00 \%$ & 0.4746 \\
\cline { 2 - 7 } (IgD memory B \\
\cline { 2 - 7 }
\end{tabular}

Table 12: Frequency of IgD memory B cells months' 1-36 post HCT vs HD

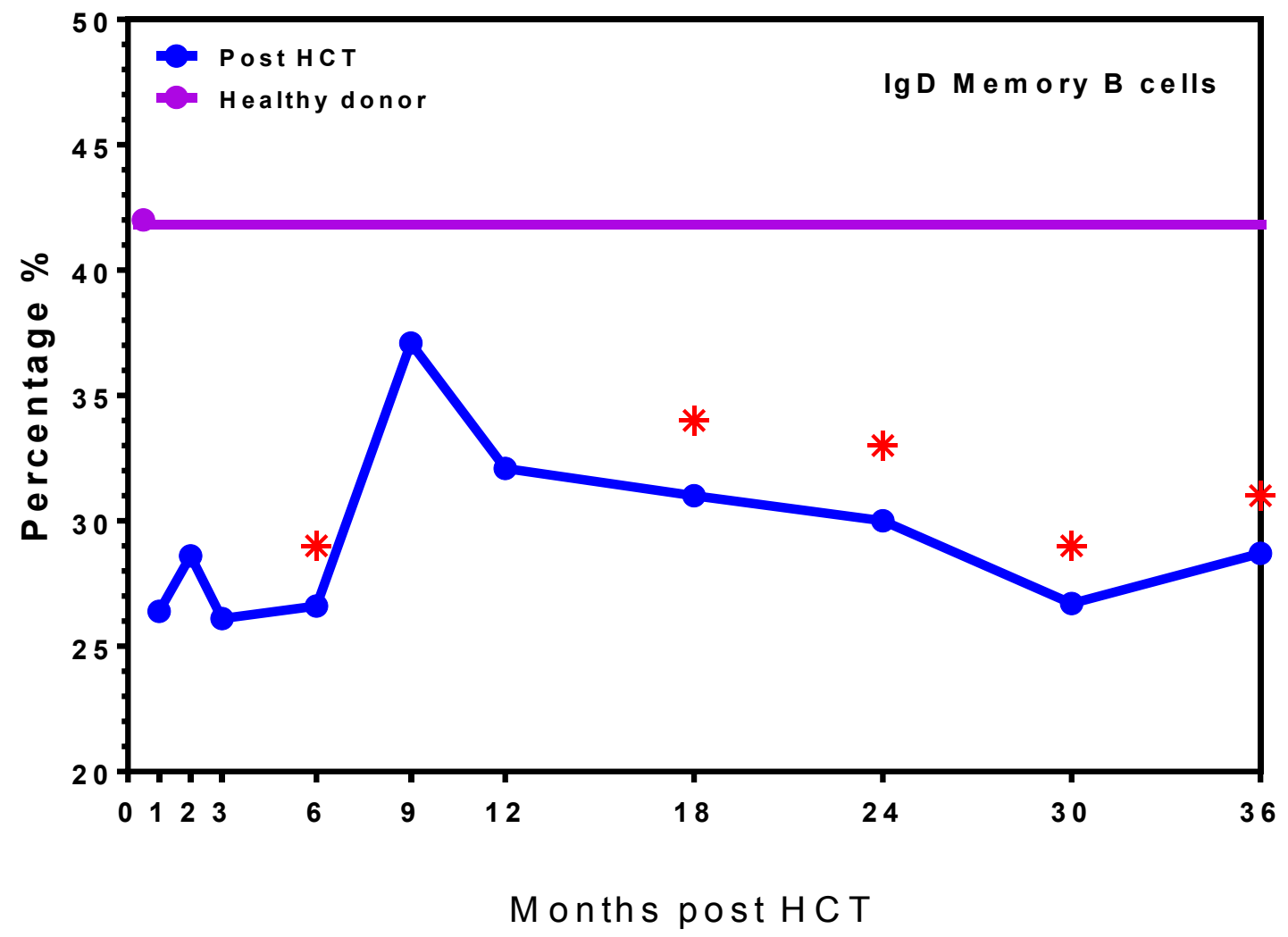

Figure 10: Frequency of IgD memory B cells vs HD (horizontal bar) * indicates significance 


\begin{tabular}{|c|c|c|c|c|c|c|}
\hline & Month & $\mathbf{N}$ & Median & Min & Max & p-value \\
\hline & HD & 19 & $0.70 \%$ & $0.00 \%$ & $4.50 \%$ & $\begin{array}{c}\text { HCT vs } \\
\text { HD }\end{array}$ \\
\cline { 2 - 7 } & 1 & 289 & $0.00 \%$ & $0.00 \%$ & $100.00 \%$ & 0.2204 \\
\cline { 2 - 7 } & 2 & 272 & $3.20 \%$ & $0.00 \%$ & $100.00 \%$ & 0.0996 \\
\cline { 2 - 7 } & 3 & 276 & $3.60 \%$ & $0.00 \%$ & $100.00 \%$ & 0.0438 \\
\cline { 2 - 7 } & 6 & 190 & $4.80 \%$ & $0.00 \%$ & $100.00 \%$ & 0.0002 \\
\cline { 2 - 7 } $\begin{array}{c}\text { IgD+CD38+ } \\
\text { (Pre germinal B } \\
\text { cells) }\end{array}$ & 9 & 177 & $4.20 \%$ & $0.00 \%$ & $75.00 \%$ & $<.0001$ \\
\cline { 2 - 7 } & 12 & 167 & $4.00 \%$ & $0.00 \%$ & $54.40 \%$ & $<.0001$ \\
\cline { 2 - 7 } & 24 & 134 & $3.60 \%$ & $0.00 \%$ & $33.30 \%$ & $<.0001$ \\
\cline { 2 - 7 } & 30 & 78 & $4.20 \%$ & $0.00 \%$ & $66.70 \%$ & $<.0001$ \\
\cline { 2 - 7 } & 36 & 55 & $2.50 \%$ & $0.00 \%$ & $50.00 \%$ & $<.0001$ \\
\hline
\end{tabular}

Table 13: Frequency of pre germinal B cells months' 1-36 post HCT vs HD

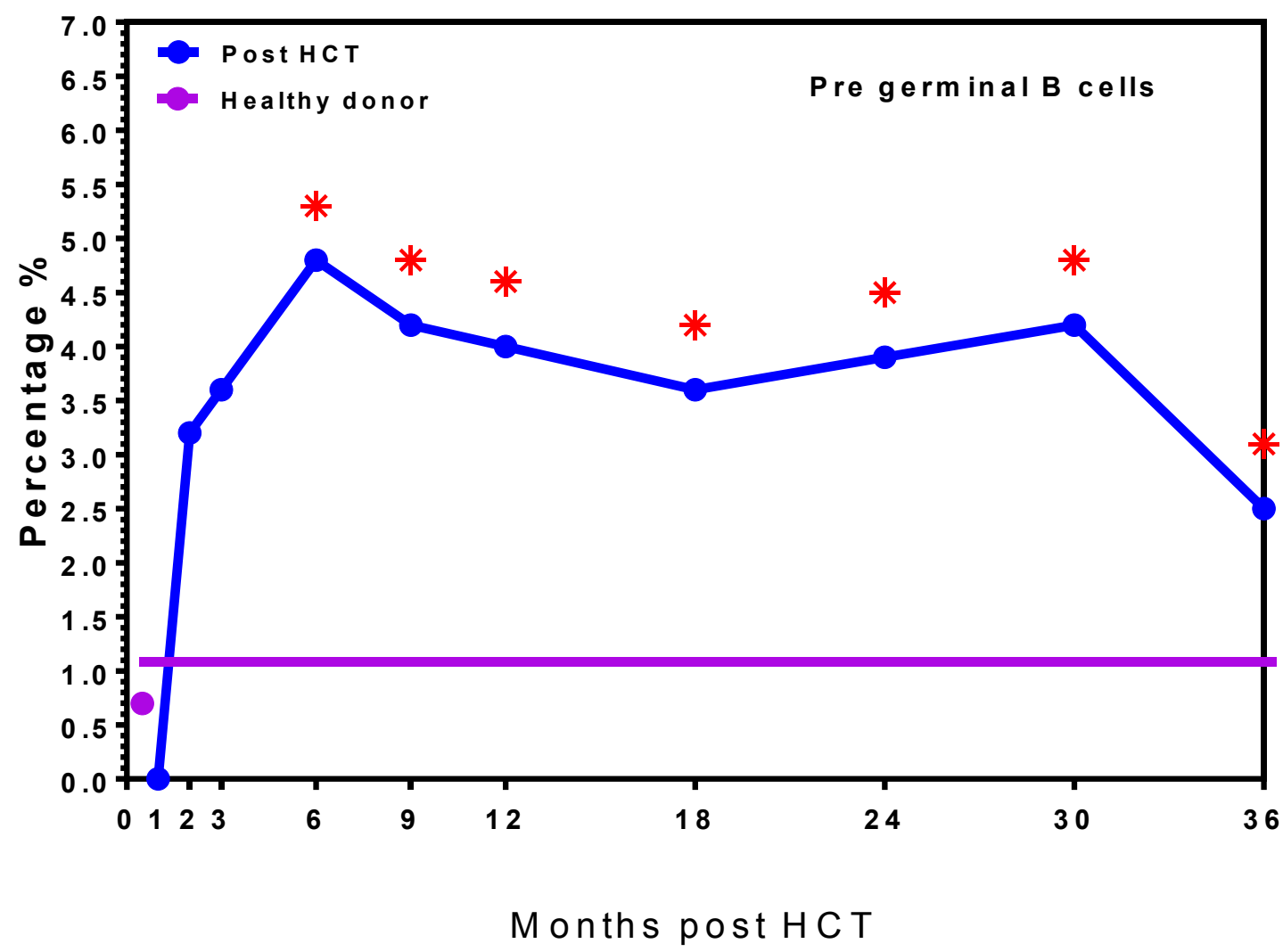

Figure 11: Frequency of pre germinal B cells vs HD (horizontal bar) * indicates significance 


\begin{tabular}{|c|c|c|c|c|c|c|}
\hline & Month & $\mathbf{N}$ & Median & Min & Max & p-value \\
\hline & HD & 19 & $54.90 \%$ & $22.40 \%$ & $82.30 \%$ & $\begin{array}{c}\text { HCT vs } \\
\text { HD }\end{array}$ \\
\cline { 2 - 7 } & 1 & 289 & $60.00 \%$ & $0.00 \%$ & $100.00 \%$ & 0.5664 \\
\cline { 2 - 7 } & 2 & 272 & $51.20 \%$ & $0.00 \%$ & $100.00 \%$ & 0.6557 \\
\cline { 2 - 7 } & 3 & 276 & $50.00 \%$ & $0.00 \%$ & $100.00 \%$ & 0.3329 \\
\cline { 2 - 7 } & 6 & 190 & $40.00 \%$ & $0.00 \%$ & $100.00 \%$ & 0.0051 \\
\cline { 2 - 7 } pCD19+27+ \\
$\begin{array}{c}\text { IgD-CD38- } \\
\text { (Post germinal } \\
\text { B cells) }\end{array}$ & 9 & 177 & $37.90 \%$ & $0.00 \%$ & $100.00 \%$ & 0.0018 \\
\cline { 2 - 7 } & 12 & 167 & $45.90 \%$ & $0.00 \%$ & $100.00 \%$ & 0.0176 \\
\cline { 2 - 7 } & 24 & 134 & $51.60 \%$ & $0.00 \%$ & $100.00 \%$ & 0.2709 \\
\cline { 2 - 7 } & 30 & 78 & $57.50 \%$ & $0.00 \%$ & $81.20 \%$ & 0.6993 \\
\cline { 2 - 7 } & 36 & 55 & $58.70 \%$ & $0.00 \%$ & $89.60 \%$ & 0.8528 \\
\hline
\end{tabular}

Table 14: Frequency of post germinal B cells months' 1-36 post HCT vs HD

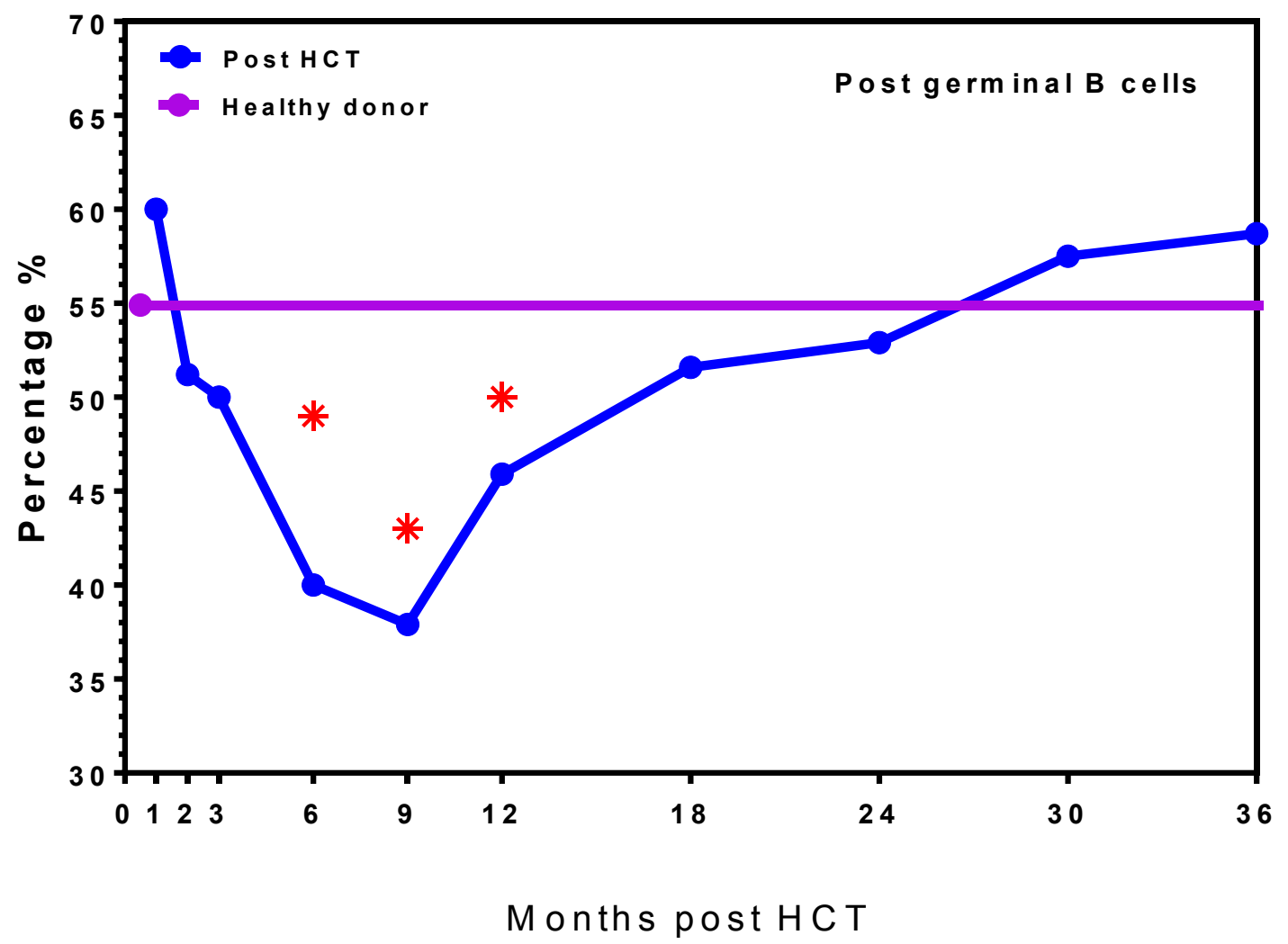

Figure 12: Frequency of post germinal B cells vs HD (horizontal bar) * indicates significance 


\begin{tabular}{|c|c|c|c|c|c|c|}
\hline & Month & N & Median & Min & Max & p-value \\
\hline & HD & 19 & $1.10 \%$ & $0.00 \%$ & $2.90 \%$ & $\begin{array}{c}\text { HCT vs } \\
\text { HD }\end{array}$ \\
\cline { 2 - 7 } & 1 & 289 & $0.00 \%$ & $0.00 \%$ & $60.10 \%$ & 0.0569 \\
\cline { 2 - 7 } & 2 & 272 & $0.00 \%$ & $0.00 \%$ & $100.00 \%$ & 0.0371 \\
\cline { 2 - 7 } & 3 & 276 & $0.00 \%$ & $0.00 \%$ & $100.00 \%$ & 0.3067 \\
\cline { 2 - 7 } & 6 & 190 & $7.30 \%$ & $0.00 \%$ & $100.00 \%$ & 0.0009 \\
\cline { 2 - 7 } $\begin{array}{c}\text { IgCD19+27+CD38+ } \\
\text { (Plasmablasts) }\end{array}$ & 9 & 177 & $8.80 \%$ & $0.00 \%$ & $100.00 \%$ & $<.0001$ \\
\cline { 2 - 7 } & 12 & 167 & $9.40 \%$ & $0.00 \%$ & $66.70 \%$ & $<.0001$ \\
\cline { 2 - 7 } & 18 & 134 & $7.90 \%$ & $0.00 \%$ & $100.00 \%$ & $<.0001$ \\
\cline { 2 - 7 } & 24 & 109 & $7.60 \%$ & $0.00 \%$ & $33.80 \%$ & $<.0001$ \\
\cline { 2 - 7 } & 30 & 78 & $6.60 \%$ & $0.00 \%$ & $30.30 \%$ & $<.0001$ \\
\hline
\end{tabular}

Table 15: Frequency of plasmablasts vs HD

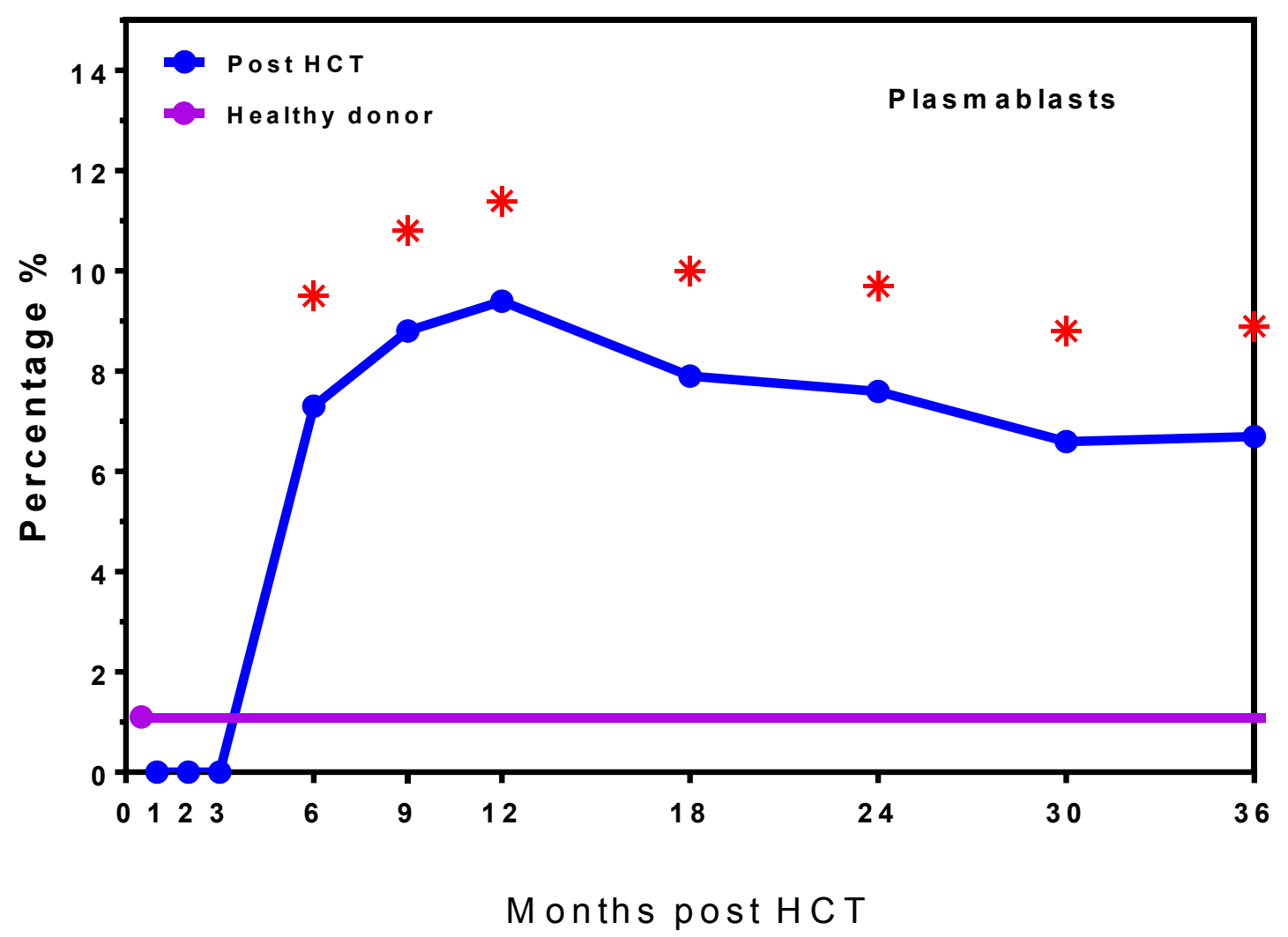

Figure 13: Frequency of plasmablasts vs HD (horizontal bar) * indicates significance 


\begin{tabular}{|c|c|c|c|c|c|c|c|c|c|c|}
\hline & & & & $\mathbf{A C}$ & & & & & & p-value \\
\hline & Month & $\mathrm{N}$ & Median & Min & Max & $\mathrm{N}$ & Median & Min & Max & $M$ vs $R$ \\
\hline & 1 & 67 & 5.8 & 0.4 & 114.9 & 222 & 4.6 & 0 & 158 & 0.0727 \\
\hline & 2 & 69 & 21.5 & 0 & 414.9 & 203 & 9.3 & 0.1 & 297.6 & 0.0001 \\
\hline & 3 & 74 & 28 & 0 & 337.6 & 202 & 17.4 & 0 & 335.9 & 0.0326 \\
\hline & 6 & 59 & 62.9 & 2 & 1315.4 & 131 & 42 & 0 & 779.7 & 0.0877 \\
\hline aCD20 & 9 & 47 & 168.8 & 3.9 & 785.2 & 130 & 104.1 & 0 & 2058 & 0.2222 \\
\hline & 12 & 43 & 203.1 & 0.1 & 1876.8 & 124 & 129.9 & 0 & 1639.1 & 0.0459 \\
\hline & 18 & 37 & 336.7 & 3.7 & 1517.8 & 97 & 189.7 & 1.2 & 1697.5 & 0.0916 \\
\hline & 24 & 28 & 241.9 & 8 & 952.8 & 81 & 232.9 & 6.9 & 1952.5 & 0.5302 \\
\hline & 30 & 21 & 421.9 & 3.2 & 1699.4 & 57 & 253.2 & 7.6 & 2413.7 & 0.0323 \\
\hline & 36 & 12 & 425 & 9.3 & 1258.8 & 43 & 348.7 & 6.1 & 1766 & 0.482 \\
\hline
\end{tabular}

Table 16: Absolute numbers of total B cells MAC vs RIC months' 1-36 post HCT vs HD

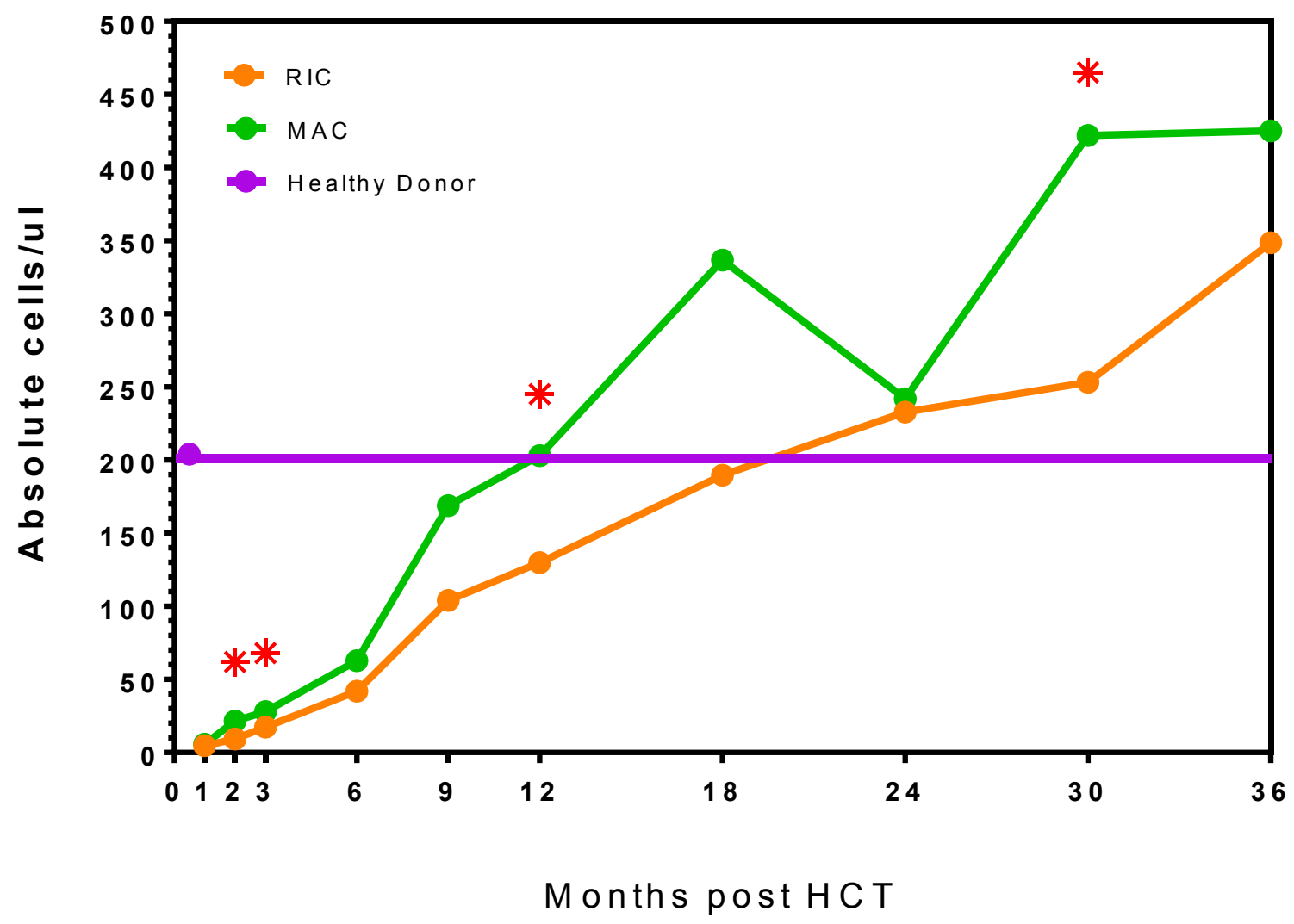

Figure 14: Absolute numbers of total B cells MAC vs RIC * indicates significance 


\begin{tabular}{|c|c|c|c|c|c|c|c|c|c|c|}
\hline & & \multicolumn{4}{|c|}{ MAC } & \multicolumn{4}{c|}{ RIC } & p-value \\
\hline \multirow{4}{*}{} & Month & $\mathrm{N}$ & Median & Min & Max & $\mathrm{N}$ & Median & Min & Max & $\begin{array}{c}\text { MAC vs } \\
\text { RIC }\end{array}$ \\
\cline { 2 - 12 } & 1 & 67 & 1.2 & 0 & 58.5 & 222 & 1.1 & 0 & 21.1 & 0.1761 \\
\cline { 2 - 12 } & 2 & 69 & 1.7 & 0 & 32.5 & 203 & 0.9 & 0 & 150.9 & 0.0037 \\
\cline { 2 - 12 } & 3 & 74 & 2.4 & 0 & 60.1 & 202 & 1.2 & 0 & 333 & 0.0069 \\
\cline { 2 - 12 } \\
\cline { 2 - 11 } $\begin{array}{l}\text { andigen } \\
\text { Experienced }\end{array}$ & 6 & 59 & 3.1 & 0 & 31.7 & 131 & 1.6 & 0 & 84.4 & 0.0031 \\
\cline { 2 - 11 } & 9 & 47 & 5.7 & 0.1 & 47 & 130 & 3.5 & 0 & 116.8 & 0.0844 \\
\cline { 2 - 11 } & 12 & 43 & 9.8 & 0 & 449.8 & 124 & 4.4 & 0 & 61.6 & 0.0221 \\
\cline { 2 - 11 } & 18 & 37 & 14.2 & 0.2 & 82.5 & 97 & 6.6 & 0.1 & 97.1 & 0.015 \\
\cline { 2 - 11 } & 24 & 28 & 17 & 1.1 & 524.5 & 81 & 9.2 & 0.1 & 94 & 0.0151 \\
\cline { 2 - 11 } & 30 & 21 & 22.7 & 0.9 & 142.2 & 57 & 9.8 & 0.1 & 72.2 & 0.0052 \\
\cline { 2 - 10 } & 36 & 12 & 29.6 & 2.7 & 71.8 & 43 & 11.3 & 0.1 & 106.1 & 0.0967 \\
\hline
\end{tabular}

Table 17: Absolute numbers of antigen experienced cells MAC vs RIC months' 1-36 post HCT vs HD

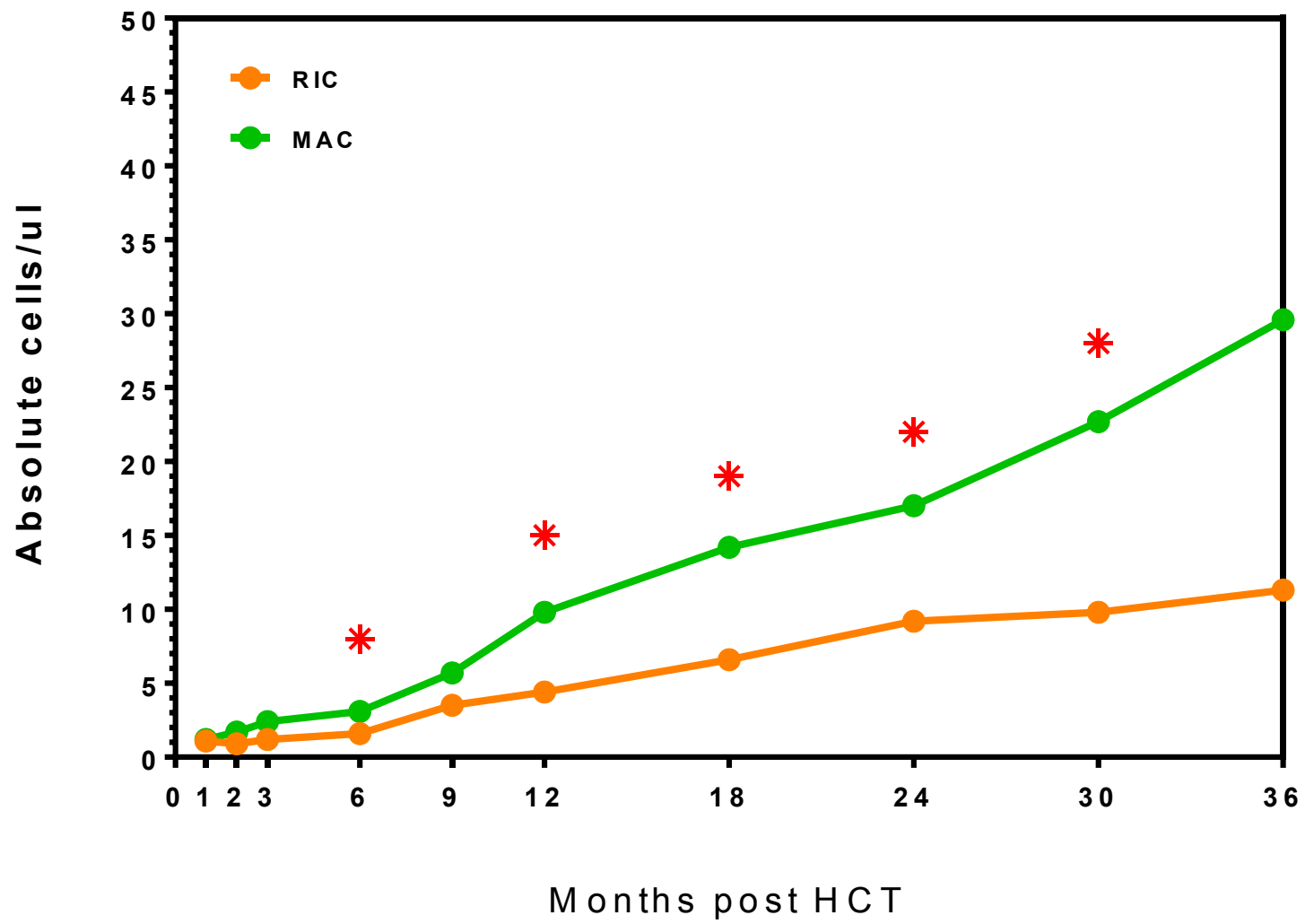

Figure 15: Absolute numbers of antigen experienced cells MAC vs RIC * indicates significance 


\begin{tabular}{|c|c|c|c|c|c|c|c|c|c|c|}
\hline & & & & MAC & & & & RIC & & $\begin{array}{c}\text { p- } \\
\text { value }\end{array}$ \\
\hline \multirow{11}{*}{$\begin{array}{l}\text { pCD19+27-IgD+CD38- } \\
\text { (Naive B cells) }\end{array}$} & Month & $\mathrm{N}$ & Median & Min & Max & $\mathrm{N}$ & Median & Min & Max & $\begin{array}{c}\mathrm{M} \text { vs } \\
\mathrm{R}\end{array}$ \\
\hline & 1 & 67 & $66.10 \%$ & $0.00 \%$ & $100.00 \%$ & 222 & $77.60 \%$ & $0.00 \%$ & $100.00 \%$ & 0.0595 \\
\hline & 2 & 69 & $36.70 \%$ & $0.00 \%$ & $91.10 \%$ & 203 & $54.50 \%$ & $0.00 \%$ & $100.00 \%$ & 0.0278 \\
\hline & 3 & 74 & $71.30 \%$ & $0.00 \%$ & $100.00 \%$ & 202 & $66.90 \%$ & $0.00 \%$ & $100.00 \%$ & 0.2714 \\
\hline & 6 & 59 & $71.10 \%$ & $14.00 \%$ & $91.60 \%$ & 131 & $74.20 \%$ & $0.00 \%$ & $100.00 \%$ & 0.1123 \\
\hline & 9 & 47 & $82.50 \%$ & $20.20 \%$ & $97.50 \%$ & 130 & $82.50 \%$ & $0.00 \%$ & $97.80 \%$ & 0.5532 \\
\hline & 12 & 43 & $81.80 \%$ & $0.00 \%$ & $94.50 \%$ & 124 & $87.00 \%$ & $0.00 \%$ & $98.60 \%$ & 0.0024 \\
\hline & 18 & 37 & $85.30 \%$ & $55.20 \%$ & $94.10 \%$ & 97 & $88.80 \%$ & $46.20 \%$ & $98.90 \%$ & 0.0189 \\
\hline & 24 & 28 & $85.00 \%$ & $69.40 \%$ & $96.50 \%$ & 81 & $87.50 \%$ & $10.00 \%$ & $97.90 \%$ & 0.1852 \\
\hline & 30 & 21 & $85.30 \%$ & $59.50 \%$ & $93.70 \%$ & 57 & $87.30 \%$ & $62.70 \%$ & $98.00 \%$ & 0.0615 \\
\hline & 36 & 12 & $80.10 \%$ & $52.40 \%$ & $93.10 \%$ & 43 & $89.00 \%$ & $72.50 \%$ & $97.70 \%$ & 0.0122 \\
\hline \multirow{10}{*}{$\begin{array}{l}\text { pCD19+27-IgD+CD38+ } \\
\text { (Transitional B cells) }\end{array}$} & 1 & 67 & $13.60 \%$ & $0.00 \%$ & $70.00 \%$ & 222 & $5.60 \%$ & $0.00 \%$ & $66.70 \%$ & 0.0002 \\
\hline & 2 & 69 & $35.90 \%$ & $0.00 \%$ & $90.10 \%$ & 203 & $28.30 \%$ & $0.00 \%$ & $89.70 \%$ & 0.0339 \\
\hline & 3 & 74 & $19.90 \%$ & $0.00 \%$ & $85.70 \%$ & 202 & $23.80 \%$ & $0.00 \%$ & $100.00 \%$ & 0.2535 \\
\hline & 6 & 59 & $24.70 \%$ & $0.00 \%$ & $84.20 \%$ & 131 & $19.70 \%$ & $0.00 \%$ & $66.70 \%$ & 0.0221 \\
\hline & 9 & 47 & $13.30 \%$ & $1.10 \%$ & $73.20 \%$ & 130 & $11.70 \%$ & $0.00 \%$ & $84.70 \%$ & 0.3645 \\
\hline & 12 & 43 & $12.90 \%$ & $0.00 \%$ & $61.10 \%$ & 124 & $9.00 \%$ & $0.00 \%$ & $69.60 \%$ & 0.0233 \\
\hline & 18 & 37 & $10.90 \%$ & $0.00 \%$ & $43.10 \%$ & 97 & $7.30 \%$ & $0.00 \%$ & $38.50 \%$ & 0.0228 \\
\hline & 24 & 28 & $9.90 \%$ & $0.60 \%$ & $29.10 \%$ & 81 & $7.30 \%$ & $0.00 \%$ & $31.00 \%$ & 0.0646 \\
\hline & 30 & 21 & $9.90 \%$ & $2.60 \%$ & $36.00 \%$ & 57 & $7.50 \%$ & $0.10 \%$ & $34.90 \%$ & 0.0672 \\
\hline & 36 & 12 & $8.00 \%$ & $0.00 \%$ & $21.50 \%$ & 43 & $7.00 \%$ & $0.00 \%$ & $22.10 \%$ & 0.7911 \\
\hline \multirow{8}{*}{$\begin{array}{l}\text { pCD19+27+ IgD+CD38- } \\
\text { (IgD memory B cells) }\end{array}$} & Month & $\mathrm{N}$ & Median & Min & Max & $\mathrm{N}$ & Median & Min & Max & $\begin{array}{c}M \text { vs } \\
R\end{array}$ \\
\hline & 6 & 59 & $26.00 \%$ & $0.00 \%$ & $72.20 \%$ & 131 & $27.30 \%$ & $0.00 \%$ & $98.20 \%$ & 0.2539 \\
\hline & 9 & 47 & $32.40 \%$ & $0.00 \%$ & $100.00 \%$ & 130 & $41.10 \%$ & $0.00 \%$ & $100.00 \%$ & 0.2885 \\
\hline & 12 & 43 & $29.20 \%$ & $0.00 \%$ & $81.00 \%$ & 124 & $34.30 \%$ & $0.00 \%$ & $92.00 \%$ & 0.0406 \\
\hline & 18 & 37 & $29.00 \%$ & $0.00 \%$ & $65.00 \%$ & 97 & $34.00 \%$ & $0.00 \%$ & $89.70 \%$ & 0.0377 \\
\hline & 24 & 28 & $34.00 \%$ & $10.50 \%$ & $94.10 \%$ & 81 & $26.70 \%$ & $0.00 \%$ & $90.70 \%$ & 0.0547 \\
\hline & 30 & 21 & $22.80 \%$ & $11.00 \%$ & $67.70 \%$ & 57 & $32.10 \%$ & $6.90 \%$ & $100.00 \%$ & 0.1462 \\
\hline & 36 & 12 & $16.00 \%$ & $3.20 \%$ & $52.80 \%$ & 43 & $30.70 \%$ & $4.80 \%$ & $93.00 \%$ & 0.0367 \\
\hline \multirow{8}{*}{$\begin{array}{l}\text { pCD19+27+IgD }+ \text { CD38+(Pre } \\
\text { Germinal B cells })\end{array}$} & Month & $\mathrm{N}$ & Median & Min & Max & $\mathrm{N}$ & Median & Min & Max & $\begin{array}{c}\text { M vs } \\
\text { R }\end{array}$ \\
\hline & 6 & 59 & $4.80 \%$ & $0.00 \%$ & $100.00 \%$ & 131 & $4.70 \%$ & $0.00 \%$ & $100.00 \%$ & 0.6965 \\
\hline & 9 & 47 & $4.20 \%$ & $0.00 \%$ & $75.00 \%$ & 130 & $4.20 \%$ & $0.00 \%$ & $66.70 \%$ & 0.5676 \\
\hline & 12 & 43 & $4.00 \%$ & $0.00 \%$ & $54.40 \%$ & 124 & $4.00 \%$ & $0.00 \%$ & $50.00 \%$ & 0.7638 \\
\hline & 18 & 37 & $3.40 \%$ & $0.00 \%$ & $28.60 \%$ & 97 & $3.70 \%$ & $0.00 \%$ & $33.30 \%$ & 0.6849 \\
\hline & 24 & 28 & $4.40 \%$ & $0.00 \%$ & $48.60 \%$ & 81 & $3.80 \%$ & $0.00 \%$ & $100.00 \%$ & 0.6875 \\
\hline & 30 & 21 & $4.10 \%$ & $0.00 \%$ & $66.70 \%$ & 57 & $4.20 \%$ & $0.00 \%$ & $41.70 \%$ & 0.7481 \\
\hline & 36 & 12 & $2.50 \%$ & $0.00 \%$ & $22.90 \%$ & 43 & $2.50 \%$ & $0.00 \%$ & $50.00 \%$ & 0.8625 \\
\hline $\begin{array}{l}\text { pCD19+27+IgD-CD38-(Post } \\
\text { Germinal B cells) }\end{array}$ & Month & $\mathrm{N}$ & Median & Min & Max & $\mathrm{N}$ & Median & Min & Max & $\begin{array}{c}\text { M vs } \\
\mathrm{R}\end{array}$ \\
\hline
\end{tabular}




\begin{tabular}{|c|c|c|c|c|c|c|c|c|c|c|}
\hline & 6 & 59 & $34.50 \%$ & $0.00 \%$ & $92.30 \%$ & 131 & $41.50 \%$ & $0.00 \%$ & $100.00 \%$ & 0.1688 \\
\hline & 9 & 47 & $34.90 \%$ & $0.00 \%$ & $76.40 \%$ & 130 & $38.50 \%$ & $0.00 \%$ & $100.00 \%$ & 1 \\
\hline & 12 & 43 & $45.70 \%$ & $1.40 \%$ & $100.00 \%$ & 124 & $46.10 \%$ & $0.00 \%$ & $84.60 \%$ & 0.5817 \\
\hline & 18 & 37 & $56.10 \%$ & $11.60 \%$ & $100.00 \%$ & 97 & $50.00 \%$ & $0.00 \%$ & $100.00 \%$ & 0.0756 \\
\hline & 24 & 28 & $48.30 \%$ & $0.00 \%$ & $77.80 \%$ & 81 & $53.00 \%$ & $0.00 \%$ & $87.50 \%$ & 0.2235 \\
\hline & 30 & 21 & $58.70 \%$ & $9.90 \%$ & $80.80 \%$ & 57 & $57.10 \%$ & $0.00 \%$ & $81.20 \%$ & 0.4077 \\
\hline & 36 & 12 & $65.80 \%$ & $30.70 \%$ & $89.60 \%$ & 43 & $55.80 \%$ & $0.00 \%$ & $85.60 \%$ & 0.0927 \\
\hline \multirow{8}{*}{$\begin{array}{l}\text { pCD19+27+IgD- } \\
\text { CD38+(Plasmablasts) }\end{array}$} & Month & $\mathrm{N}$ & Median & Min & Max & $\mathrm{N}$ & Median & Min & Max & $\begin{array}{c}\text { M vs } \\
\mathrm{R}\end{array}$ \\
\hline & 6 & 59 & $12.50 \%$ & $0.00 \%$ & $69.20 \%$ & 131 & $5.90 \%$ & $0.00 \%$ & $100.00 \%$ & 0.0103 \\
\hline & 9 & 47 & $12.50 \%$ & $0.00 \%$ & $63.70 \%$ & 130 & $7.70 \%$ & $0.00 \%$ & $100.00 \%$ & 0.1021 \\
\hline & 12 & 43 & $12.90 \%$ & $0.00 \%$ & $61.70 \%$ & 124 & $7.20 \%$ & $0.00 \%$ & $66.70 \%$ & 0.0985 \\
\hline & 18 & 37 & $10.70 \%$ & $0.00 \%$ & $41.70 \%$ & 97 & $6.70 \%$ & $0.00 \%$ & $100.00 \%$ & 0.0589 \\
\hline & 24 & 28 & $4.90 \%$ & $0.00 \%$ & $25.10 \%$ & 81 & $8.20 \%$ & $0.00 \%$ & $33.80 \%$ & 0.1358 \\
\hline & 30 & 21 & $8.20 \%$ & $0.50 \%$ & $23.40 \%$ & 57 & $5.20 \%$ & $0.00 \%$ & $30.30 \%$ & 0.0808 \\
\hline & 36 & 12 & $7.40 \%$ & $3.40 \%$ & $22.00 \%$ & 43 & $6.00 \%$ & $0.00 \%$ & $36.60 \%$ & 0.21 \\
\hline
\end{tabular}

Table 18: Frequency of B cell subsets MAC vs RIC 


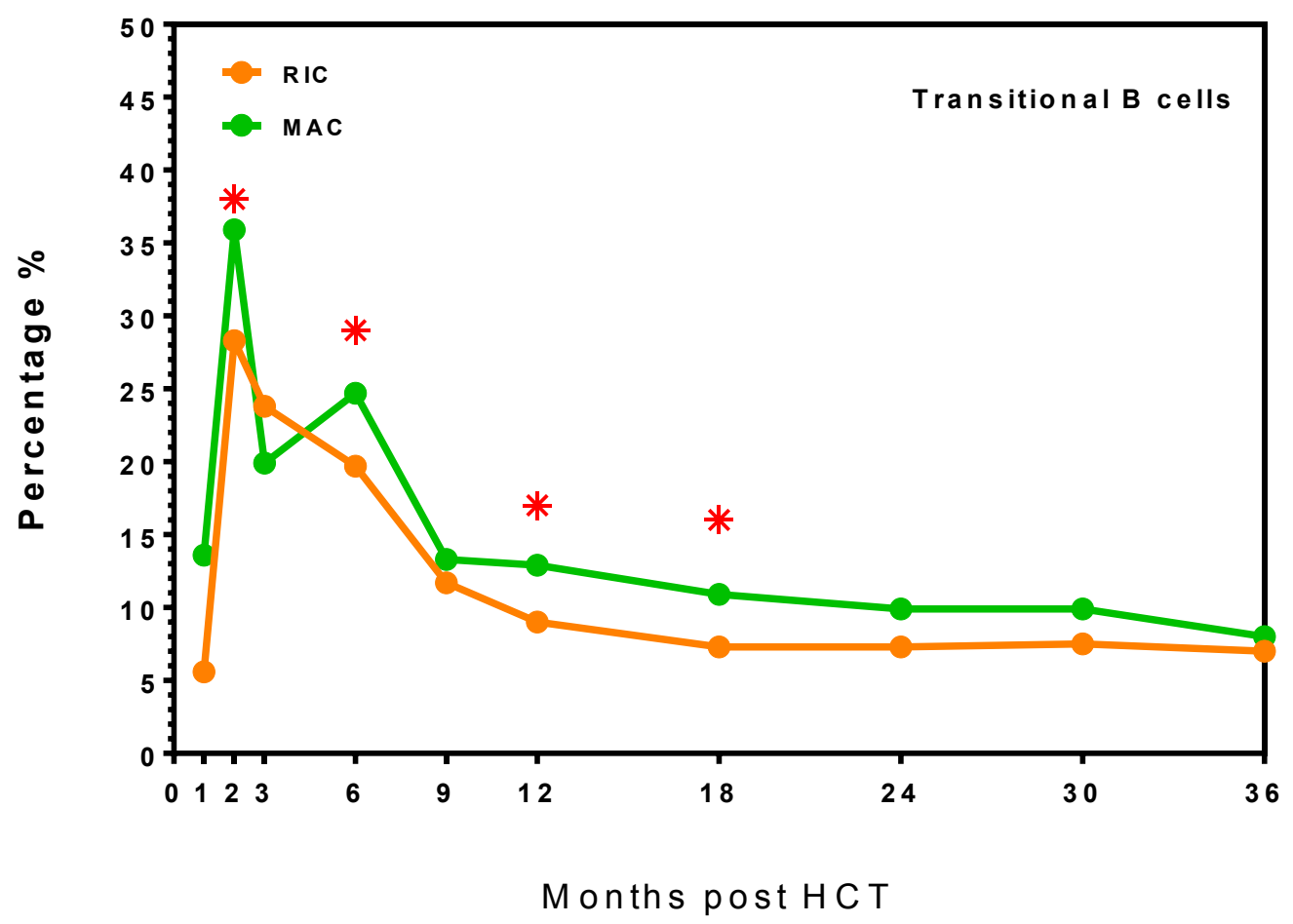

Figure 16: Frequency profile of transitional B cells MAC vs RIC. * indicates significance

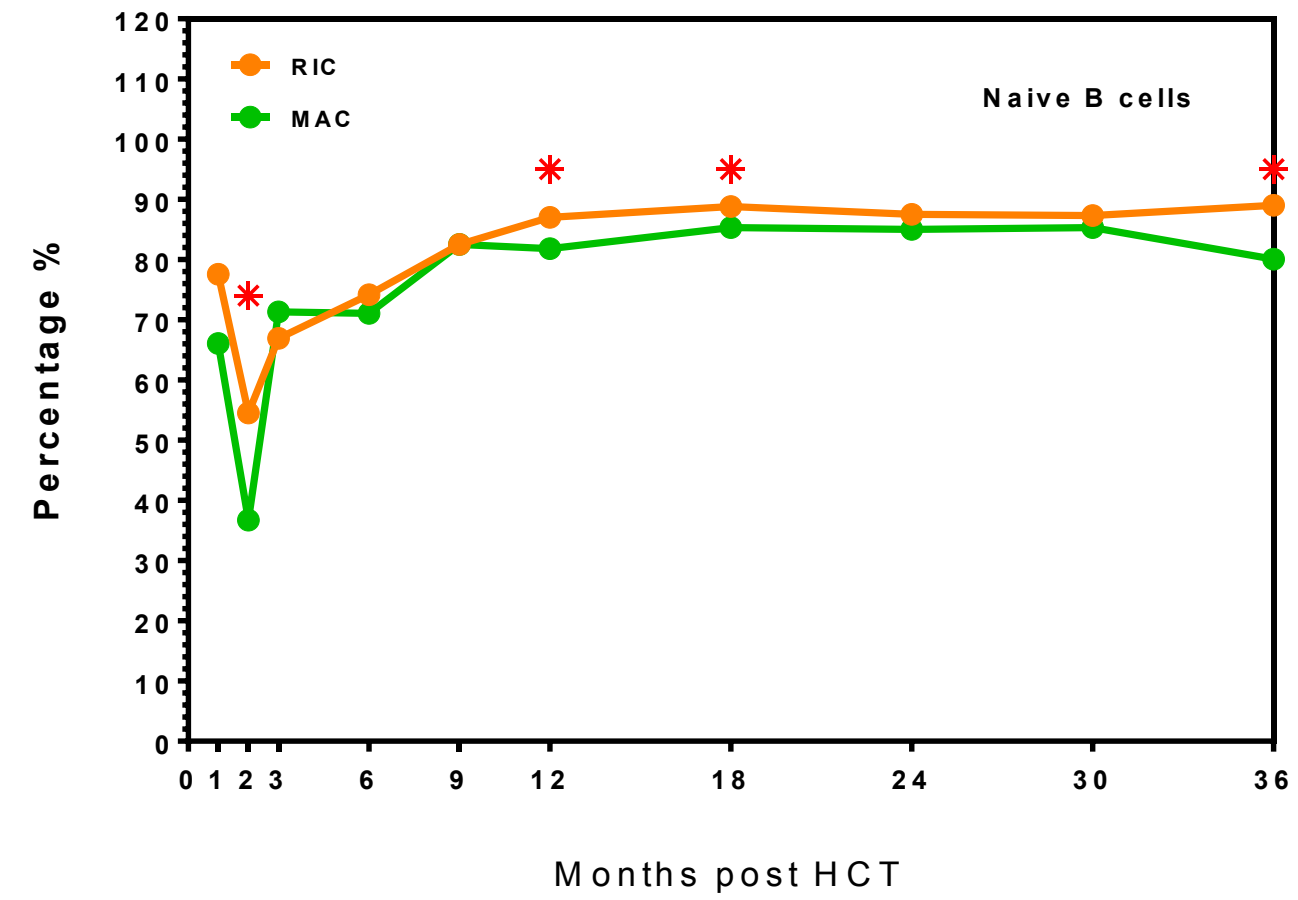

Figure 17: Frequency profile of naïve B cells MAC vs RIC. * indicates significance 


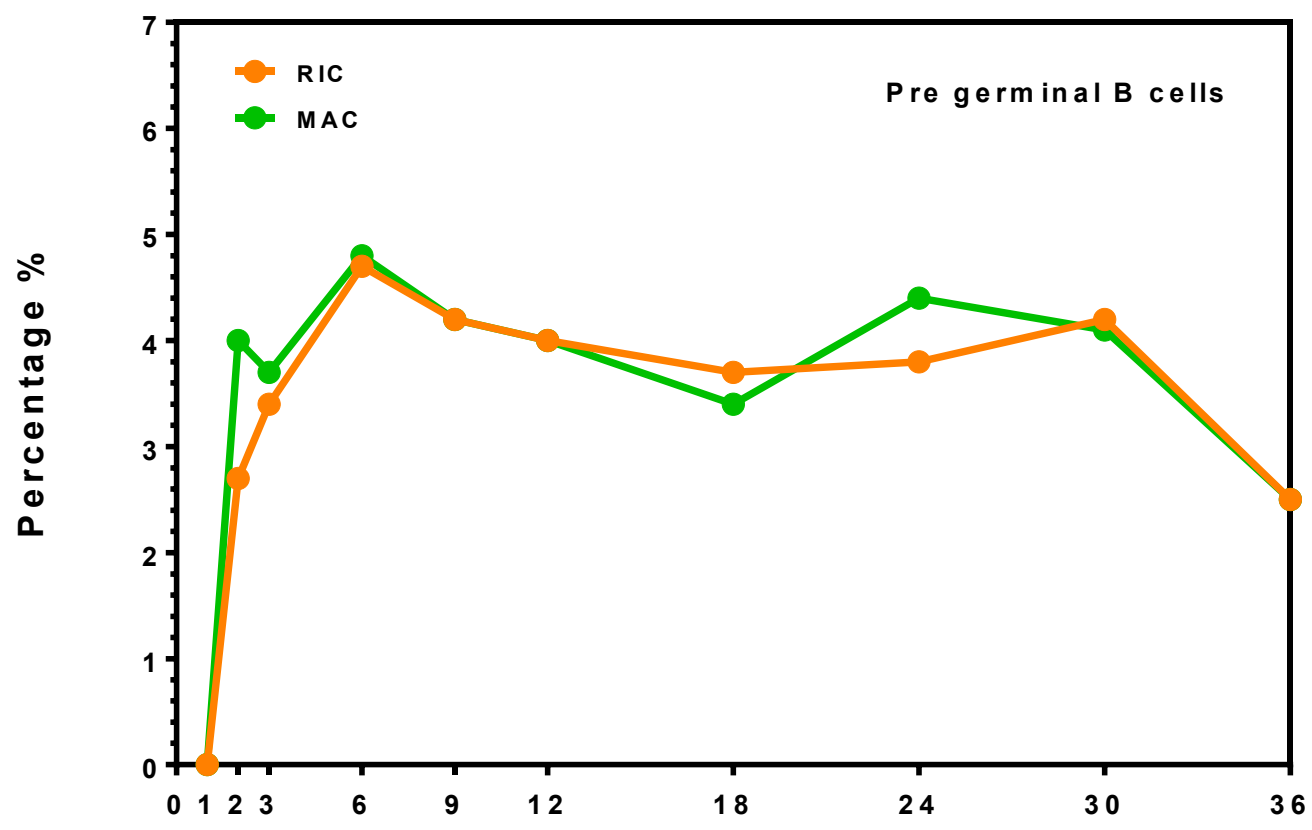

Months post $\mathrm{HCT}$

Figure 18: Frequency profile of pre germinal B cells MAC vs RIC

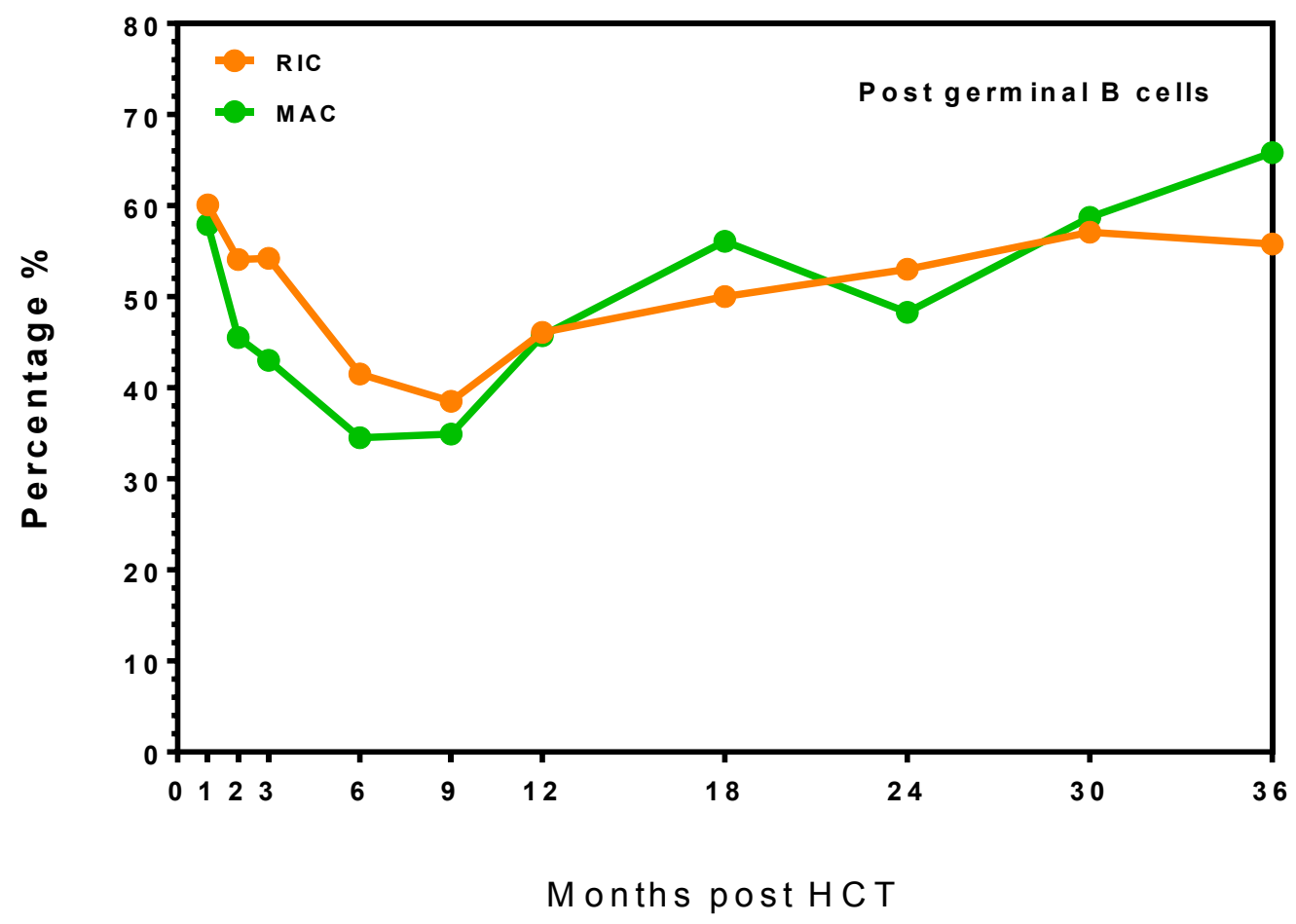

Figure 19: Frequency profile of post germinal B cells MAC vs RIC 


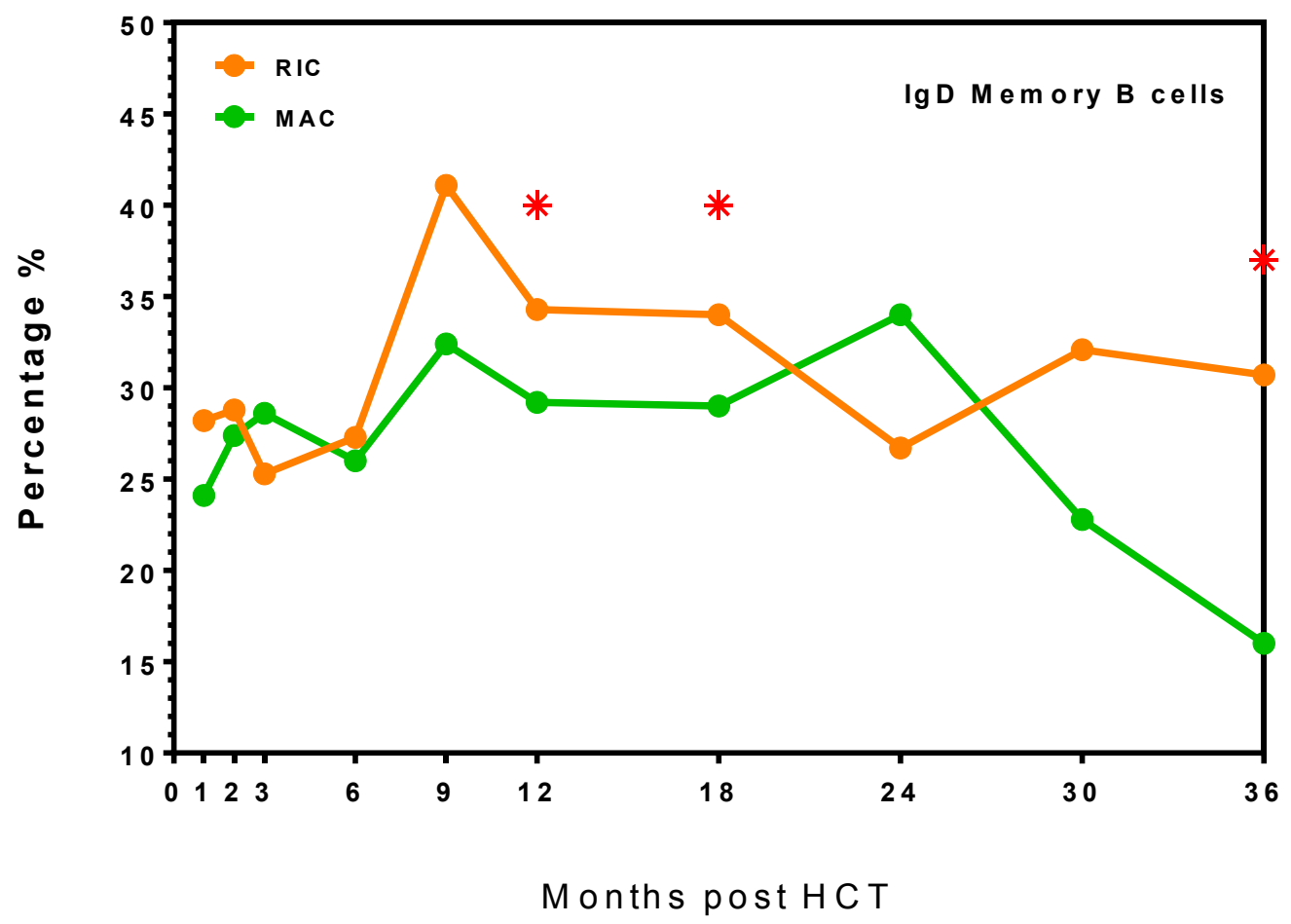

Figure 20: Frequency profile of IgD memory B cells MAC vs RIC. * indicates significance

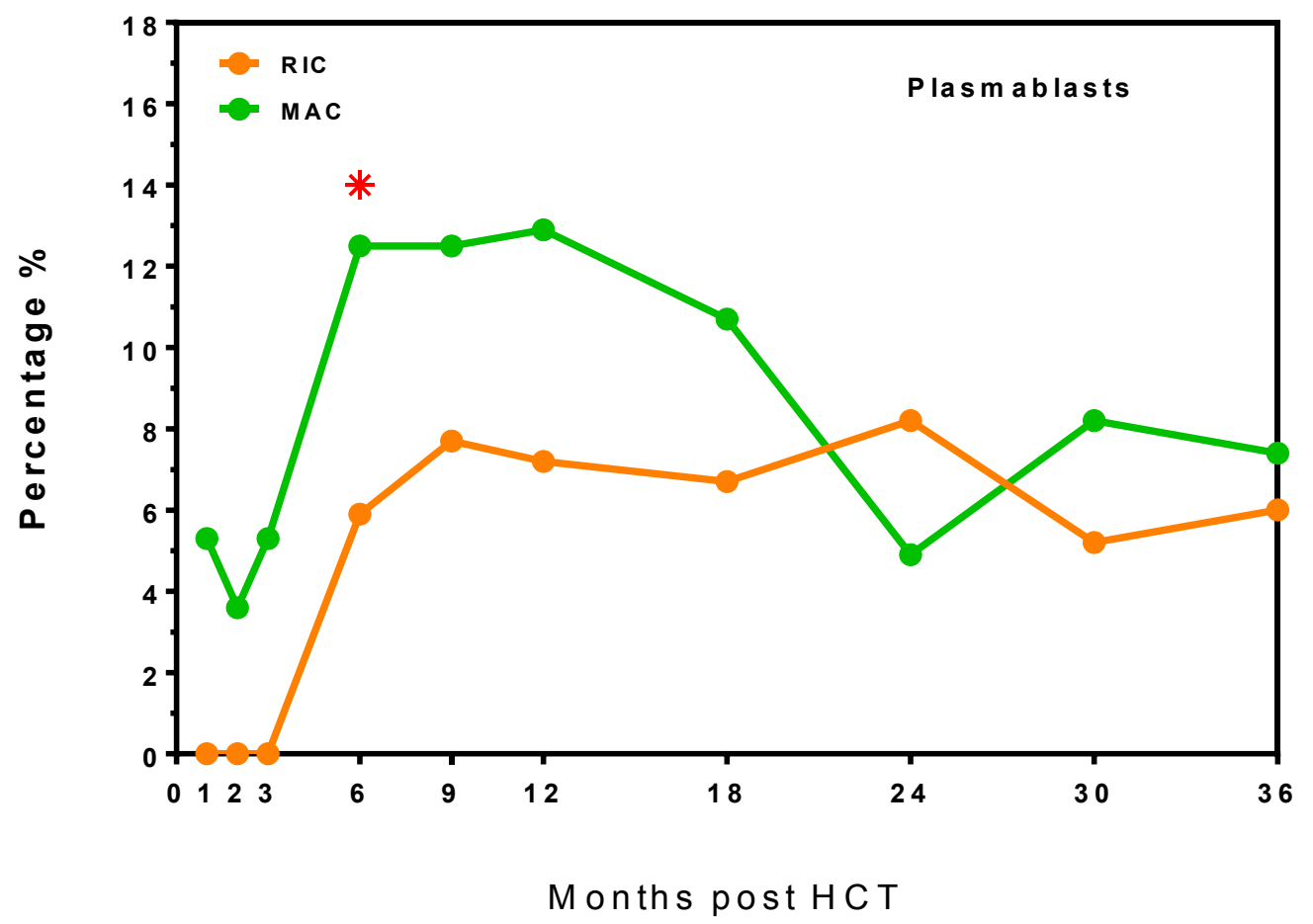

Figure 21: Frequency profile of plasmablasts MAC vs RIC. * indicates significance 